\title{
Investigating the thermal stability of irradiation-induced damage in a zirconium alloy with novel in situ techniques
}

DOI:

10.1016/j.actamat.2017.11.051

\section{Document Version}

Accepted author manuscript

Link to publication record in Manchester Research Explorer

\section{Citation for published version (APA):}

Topping, M., Ungar, H. T., Race, C., Harte, A., Garner, A., Baxter, F., Dumbill, S., Frankel, P., \& Preuss, M. (2017). Investigating the thermal stability of irradiation-induced damage in a zirconium alloy with novel in situ techniques. Acta Materialia, 145, 255-263. https://doi.org/10.1016/j.actamat.2017.11.051

\section{Published in:}

Acta Materialia

\section{Citing this paper}

Please note that where the full-text provided on Manchester Research Explorer is the Author Accepted Manuscript or Proof version this may differ from the final Published version. If citing, it is advised that you check and use the publisher's definitive version.

\section{General rights}

Copyright and moral rights for the publications made accessible in the Research Explorer are retained by the authors and/or other copyright owners and it is a condition of accessing publications that users recognise and abide by the legal requirements associated with these rights.

\section{Takedown policy}

If you believe that this document breaches copyright please refer to the University of Manchester's Takedown Procedures [http://man.ac.uk/04Y6Bo] or contact uml.scholarlycommunications@manchester.ac.uk providing relevant details, so we can investigate your claim.

\section{OPEN ACCESS}




\title{
Investigating the thermal stability of irradiation-induced damage in a zirconium alloy with novel in situ techniques
}

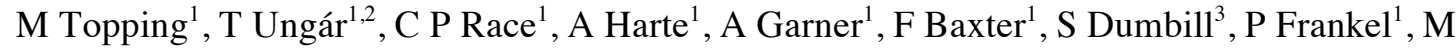 \\ Preuss $^{1}$ \\ ${ }^{I}$ Materials Performance Centre, School of Materials, The University of Manchester, \\ Manchester M13 9PL, United Kingdom \\ ${ }^{2}$ Department of Materials Physics, Eötvös University, $P O B$ 32, Hungary \\ ${ }^{3}$ National Nuclear Laboratory, Sellafield, Seascale, Cumbria, CA20 1PG, United Kingdom
}

Keywords: zirconium; annealing; dislocations; line profile analysis; in situ.

\begin{abstract}
$\mathrm{Zr}$ alloys exhibit irradiation-induced growth and hardening which is associated with the defects and dislocation loops that form during irradiation. In this study, state-of-the-art in-situ synchrotron X-ray diffraction (SXRD) and transmission electron microscopy (TEM) techniques were used to investigate the stability of dislocation loops in two proton-irradiated Zr-Fe binary alloys in real time. Complementary data from both techniques show rapid annealing of a-loops occurs between $300^{\circ} \mathrm{C}$ and $450^{\circ} \mathrm{C}$. Line profile analysis was performed on the SXRD patterns using the convoluted multiple whole profile analysis tool, to calculate the change in a-loop line density as a function of post-irradiation heat treatment temperature and time. At temperatures below $300^{\circ} \mathrm{C}$, no significant decrease in a-loop density was detected when held for one hour at temperature. From this SXRD experiment, we calculate the effective activation energy for the annealing process as $0.46 \mathrm{eV}$. On-axis in-situ STEM imaging was used to directly observe a-loop mobility during heating cycles and confirm that a-loops begin to glide in the trace of the basal plane at $\sim 200^{\circ} \mathrm{C}$ in a thin foil specimen. Such a-loop gliding events, leading to annihilation at the foil's surfaces, became more frequent between $300-450^{\circ} \mathrm{C}$.
\end{abstract}

\subsection{Introduction}

The use of zirconium ( $\mathrm{Zr}$ ) alloys in nuclear reactor fuel assemblies is prevalent due to their low thermal neutron absorption cross-section and acceptable structural properties at reactor operating temperatures [1]. $\mathrm{Zr}$ alloys undergo irradiation-induced growth 
(IIG), one of the major life-limiting factors of the fuel assemblies, which is suggested to be due to the anisotropic diffusion of point defects generated by irradiation damage [2], and is correlated with the formation of dislocation loops [3-6]. There are two dominant types of loops that form during irradiation of $\mathrm{Zr}$ alloys, commonly referred to as a-loops and c-loops. The a-loops appear first at low dose and have a Burgers vector of $\frac{1}{3}\langle 11 \overline{2} 0\rangle$ and a habit plane of either the first or second order prismatic planes [7]. The appearance of c-loops is correlated to the onset of the accelerated growth regime, known as breakaway growth [8]. c-loops reside on the basal plane and have a Burgers vector of $\frac{1}{6}\langle 20 \overline{2} 3\rangle[9]$.

Irradiation results in a significant change to the mechanical properties of $\mathrm{Zr}$ alloys, primarily an increase in hardness [10-16]. It has been proposed that this change is due to the formation of dislocation loops and irradiation-induced precipitates, which act as barriers to dislocation movement during mechanical deformation $[11,12,17,18]$. The recovery of mechanical properties via heat treatments or temperature variations along a fuel assembly is therefore a key avenue of study for $\mathrm{Zr}$ alloys. Data generated from annealing experiments provide vital information regarding the stability of defects and may also provide insight into the mechanisms of irradiation damage. Further, it is important to predict the annealing behaviour of irradiated $\mathrm{Zr}$ alloys as residual heat during fuel waste storage could impact the structure of the irradiation-induced defects. For instance, it has been observed that the growth strain can be fully recovered in prebreakaway neutron-irradiated Zircaloy-2 specimens through annealing [3]. It is also important to understand the effect temperature has on irradiated $\mathrm{Zr}$ alloys when considering ex-situ corrosion testing in a high temperature autoclave environment.

Previous annealing studies have been performed on neutron-irradiated $\mathrm{Zr}$ alloys that contained a high density of a-loops and exhibit irradiation-induced hardening $[12,14,15,17]$. These studies have shown that post-irradiation annealing leads to recovery of the base mechanical properties for alloys containing only a-loops $[12,15,17]$. This recovery has been correlated with an overall reduction in dislocation loop density and an increase in the average loop diameter $[12,17,19]$. Ribis et al. used microhardness values, transmission electron microscopy (TEM) observations and a cluster dynamics model to show that the recovery of the hardness to non-irradiated levels is correlated with a reduction in dislocation density [12]. 
To date, the majority of experimental work has been performed ex-situ providing only snap-shots of the microstructural and mechanical property evolution during the annealing process, using transmission electron microscopy (TEM) and mechanical testing techniques. The present work aims to demonstrate the annealing of protonirradiated binary $\mathrm{Zr}-\mathrm{Fe}$ alloys in real time using novel in-situ techniques. Specially fabricated $\mathrm{Zr}$-Fe binary alloys have been used in this study to eliminate some of the complexity inherent in commercial alloy systems, whilst retaining key aspects of material evolution under irradiation, allowing the effect of specific microstructural features to be evaluated. Proton irradiation has previously been shown to be a good surrogate for neutron-irradiation in $\mathrm{Zr}$ alloys, providing similar damage structures and chemical evolution [10,20-23]. Proton irradiation allows for the design of systematic studies, achieving comparable damage levels in short timescales with low residual activity compared to neutron-irradiated samples. To the best of our knowledge this is the first study experimentally investigating the annealing behaviour of a-loops in proton-irradiated $\mathrm{Zr}$ alloys.

As well as TEM, line profile analysis has been used to investigate the dislocations formed during irradiation in $\mathrm{Zr}$ alloys. The software package, extended Convoluted Multiple Whole Profile (CMWP) was originally developed to calculate the dislocation densities in cold-worked material but has also been used previously to calculate the dislocation densities in neutron-irradiated $\mathrm{Zr}-2.5 \mathrm{Nb}$ samples [24]. Seymour et al. used CMWP to calculate dislocation densities in neutron-irradiated Zircaloy-2 and found that despite some differences in absolute dislocation densities, the trends observed with CMWP, with respect to dislocation density changes with increasing damage level, were similar to those observed in TEM investigations [25]. In this work CMWP will be used to track the change in dislocation density during the in-situ SXRD annealing experiment.

The present study aims to investigate the stability of a-loops during heating using two complementary in situ techniques. In-situ synchrotron X-ray diffraction (SXRD) was used to obtain bulk information and in situ heating in a TEM was used in a complementary investigation into the mechanisms of recovery with superior spatial and temporal resolution. These novel techniques allow for new insight into the mechanisms of defect annealing in $\mathrm{Zr}$ alloys, allowing for determination of an accurate temperature 
for the onset of annealing and for an activation energy to be calculated, which will enable better informed selection of parameters for future experiments.

\subsection{Experimental Methods}

\subsection{Material}

Fully recrystallised $\mathrm{Zr}-0.6 \mathrm{Fe}$ and $\mathrm{Zr}-0.1 \mathrm{Fe}$ (wt $\%$ ) alloys, with the characteristic split basal texture [26], were proton-irradiated at the University of Michigan Ion Beam Laboratory's 1.7 MeV Tandetron acceleration facility, operated at 2 MeV. The samples were irradiated to a damage level of $3 \mathrm{dpa}\left(3.415 \times 10^{19}\right.$ protons $\left.\mathrm{cm}^{-2}\right)$ for the $\mathrm{Zr}-0.6 \mathrm{Fe}$ alloy and $1.5 \mathrm{dpa}\left(1.708 \times 10^{19}\right.$ protons $\left.\mathrm{cm}^{-2}\right)$ for the $\mathrm{Zr}-0.1 \mathrm{Fe}$ alloy, with an irradiation temperature of $350 \pm 9^{\circ} \mathrm{C}$. The nominal dpa levels are extracted from the damage profile at a depth of $12 \mu \mathrm{m}$ from the sample surface, as shown in Figure 1. A current density of $0.2 \mu \mathrm{A} \mathrm{mm}^{-2}$ was maintained throughout the irradiation resulting in a damage rate of $\sim 1.096 \times 10^{-5} \mathrm{dpa} \mathrm{s}^{-1}$. Therefore, the $3 \mathrm{dpa}$ sample was irradiated for 76 hours and the 1.5 dpa sample was irradiated for 38 hours. The dose calculations were performed using the SRIM software package with the "Quick" Kinchin and Pease damage calculation [27] in pure $\mathrm{Zr}$ with a displacement threshold energy of $40 \mathrm{eV}$. The predicted damage profile for the 1.5 dpa sample can be seen in Figure 1, with the black vertical line indicating the region studied in the TEM, at a depth of $\sim 12 \mu \mathrm{m}$. The dose level stated for the binary Zr-Fe alloys is based on the damage level at $40 \%$ of the Bragg peak from the sample surface in order to indicate the dose in the studied plateau region of the damage profile. The damage profile shows a large dependence on depth, and therefore it is important that the flatter region of the profile is studied in order to minimise variation in damage levels within a sample.

The binary $1.5 \mathrm{dpa} \mathrm{Zr}-0.1 \mathrm{Fe}$ alloy used in this work has been investigated in detail as part of another study, looking into the effect of redistributed Fe from SPPs on dislocation densities [20]. It was found that this alloy contains $\sim 1-2 \mu \mathrm{m}$ coarse $\mathrm{Zr}_{3} \mathrm{Fe}$ secondary phase particles (SPPs) unevenly distributed throughout the sample. Close to these SPPs, which have undergone some irradiation-induced dissolution, $\mathrm{Fe}$ has been

observed to segregate to pyramidal loops with a likely Burgers vector of $\frac{1}{3}\langle 11 \overline{2} 3\rangle$ [20]. Away from the SPPs, the matrix and the dislocation structure is akin to that in pure $\mathrm{Zr}$, with no Fe clustering observed [20]. The region investigated by TEM in this study was 
$<1 \mu \mathrm{m}$ away from an SPP and so contains very low levels of Fe in the matrix. Increasing the Fe wt $\%$ in the alloy results in an increased SPP volume fraction from $<1 \%$ to $\sim 5 \%$ between the $\mathrm{Zr}-0.1 \mathrm{Fe}$ and $\mathrm{Zr}-0.6 \mathrm{Fe}$ alloys. However, the SPPs in $\mathrm{Zr}-0.6 \mathrm{Fe}$ are significantly coarser than in $\mathrm{Zr}-0.1 \mathrm{Fe}$ and hence the inter-particle spacing remains similar. Therefore, the majority of the matrix in the sample studied using SXRD will not be affected by Fe redistribution from the $\mathrm{Zr}_{3} \mathrm{Fe}$ SPPs and consequently, even though two variants of $\mathrm{Zr}-\mathrm{Fe}$ binary alloys have been studied, the slight compositional differences should not affect the validity of comparisons between samples.

\subsection{In-situ SXRD annealing of Zr-0.6Fe alloy}

In-situ SXRD annealing experiments were performed on $\mathrm{Zr}-0.6 \mathrm{Fe}$ alloy (3 dpa) at the Diamond Light Source, UK, beamline I11 [28]. I11 is a high-resolution beamline with an angular resolution of $0.001^{\circ}$, a highly parallel beam with a small energy spread, high flux and low background. A beam energy of $\sim 15 \mathrm{keV}$ (wavelength $=0.08269 \mathrm{~nm}$ ) was used. The sample was ground from the non-irradiated surface to a thickness of $200 \mu \mathrm{m}$ and punched out as a $3 \mathrm{~mm}$ disc using a disc punch. For the diffraction experiment reflection geometry was used with a fixed tilt of $5^{\circ}$. The $5^{\circ}$ tilt angle was selected to provide a maximum penetration depth of $\sim 13 \mu \mathrm{m}$, across the $2 \theta$ range of $15^{\circ}-55^{\circ}$, ensuring the diffracted X-rays originate from the plateau region of the profile, Figure 1. The footprint of the beam on the sample surface was $1 \times 1 \mathrm{~mm}^{2}$. The annealing experiment was performed in an inert atmosphere by placing the irradiated specimen in a quartz capillary with a wall thickness of $0.3 \mathrm{~mm}$, which was sealed in an argon atmosphere. The inert atmosphere was necessary to minimise oxidation of the specimen at high temperatures. A hot air gun was placed directly under the sample and the temperature was increased from 50 to $600^{\circ} \mathrm{C}$, in steps of $50^{\circ} \mathrm{C}$, with a heating rate of $1^{\circ} \mathrm{C} \mathrm{s}^{-1}$, and held for 60 minutes at each $50^{\circ} \mathrm{C}$ increment. A schematic of the experimental setup is shown in Figure 2. A series of 5-minute long scans were taken at each temperature, over the 60-minute period, in order to monitor diffraction pattern changes during the annealing process.

In order to increase the peak intensity in the patterns and so to increase statistical reliability for line profile analysis, multiple patterns were recorded at the same temperature and summed together where possible. This summation was only performed when a minimal change, in terms of peak shift and FWHM reduction across the range 
of patterns, was observed. Once the peaks had shifted, by $>1 \times 10^{-5} \mathrm{~nm}$, or sharpened, by $>0.001 \mathrm{FWHM}$, the patterns were no longer summed, as this would have resulted in artificial peak broadening. Therefore beyond $300^{\circ} \mathrm{C}$, where the patterns change rapidly, only a single pattern, the last pattern at each temperature, was used for CMWP analysis. The FWHM of each peak was determined using the fitting software Fityk with a Pearson 7 fitting algorithm.

Line profile analysis (LPA) of the SXRD patterns was used to calculate the changes in a-loop dislocation density based on the evolution of the diffraction profile during annealing. This analysis employed the extended Convoluted Multiple Whole Profile (CMWP) software package [29-33], which has been used previously to study dislocation densities in neutron-irradiated $\mathrm{Zr}$ alloys [24,25]. CMWP utilises the Wilkens model [34-36], which states that the Fourier transform of the strain contribution to a peak profile can be expressed as:

$$
F T\left(I_{h k l}^{D}\right)=A_{L}^{D}=\exp \left[-\rho\left(\frac{\pi b^{2}}{2}\right) L^{2} f(\eta) g^{2} C\right]
$$

Where $\rho$ and $\mathbf{b}$ are the dislocation density and Burgers vector respectively. $\mathbf{C}$ is the $h k l$ dependent contrast factor of the dislocation and $\mathbf{g}$ is the diffraction vector, such that $|g|=2 \sin \theta_{B} / \lambda$, where $\theta_{B}$ is the Bragg angle. $L$ is the Fourier variable and $f(\eta)$ is the strain function derived by Wilkens [36]. In this function, $\eta=L / R_{e}$ and $R_{e}$ is the effective outer cut-off radius of the dislocation strain field. A detailed description of the terms in Equation 1 has been outlined by Seymour et al [25].

\subsection{In-situ TEM annealing of $\mathrm{Zr}-0.1 \mathrm{Fe}$ alloy}

A TEM foil, from the $\mathrm{Zr}-0.1 \mathrm{Fe} 1.5 \mathrm{dpa}$ sample, was prepared via twin jet electropolishing using an electrolyte of $10 \%$ perchloric acid in methanol at $-40{ }^{\circ} \mathrm{C}$. To study the plateau region of the damage profile, $\sim 12 \mu \mathrm{m}$ was electropolished from the irradiated surface. The amount of material removed was confirmed by scanning topography of the sample using a Keyence VK-X200K 3D Laser Scanning Microscope, after which the irradiated face was protected with acid-resistant lacquer and then polished to perforation from the non-irradiated face. Subsequently, a grain orientated with the $\langle 11 \overline{2} 0\rangle$ zone axis close to the normal of the TEM foil (from the electron transparent region) was extracted using focused ion beam (FIB) milling in an FEI 
Quanta 3D dual beam FIB. The extracted grain was placed onto a Protochips Aduro Thermal E-chip with both $50 \mathrm{~nm}$ Si3N4 (E-AHA11) and amorphous carbon (EAHA21) support membranes to enable in-situ heating in the microscope using a Protochips Aduro heating holder. The sample was secured onto the membrane by

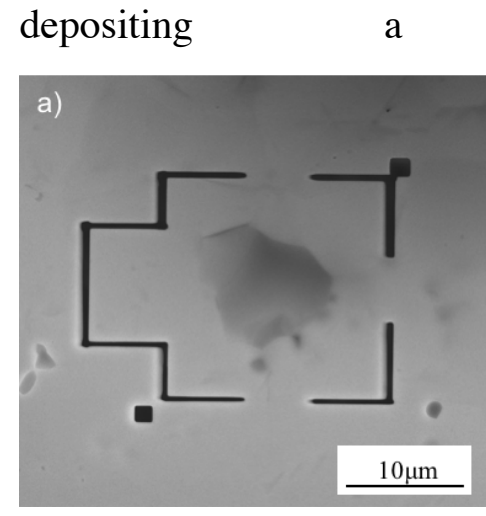
small amount

of Pt.
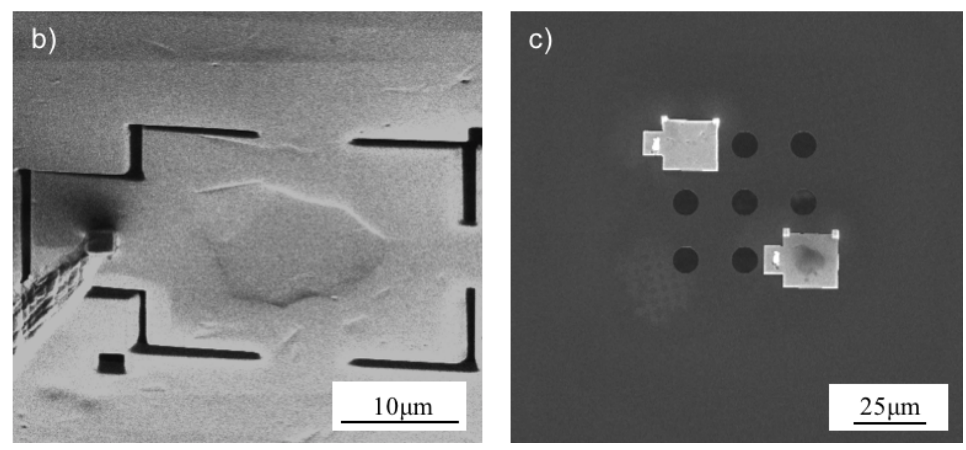

Figure 3(a) is a secondary electron (SE) image of the cuts made in the TEM foil before lift out, (b) is an ion beam image of the micromanipulator attached to the foil and (c) is a SE image of the grain placed on the heating chip. The annealing experiment was carried out in a G2 80-200 kV spherical aberration-corrected FEI Titan microscope. The microscope was operated at $200 \mathrm{kV}$ with a probe current of $600 \mathrm{pA}$. BF-STEM imaging from the $\langle 11 \overline{2} 0\rangle$ direction was used to directly observe the annealing of aloops. The sample was heated in steps of $25^{\circ} \mathrm{C}$ and held for $\sim 80$ seconds at each temperature with an image collected every 1 second. This fast acquisition resulted in some loss of image quality but enabled time-resolved imaging of any rapid microstructural changes. A non-irradiated sample was placed onto the same heating chip and subjected to the same heating process as the control sample. No microstructural changes were observed in the non-irradiated sample, even up to $600^{\circ} \mathrm{C}$.

\subsection{Results}

\section{$\underline{\text { 3.1 In-situ SXRD annealing of Zr-0.6Fe alloy }}$}




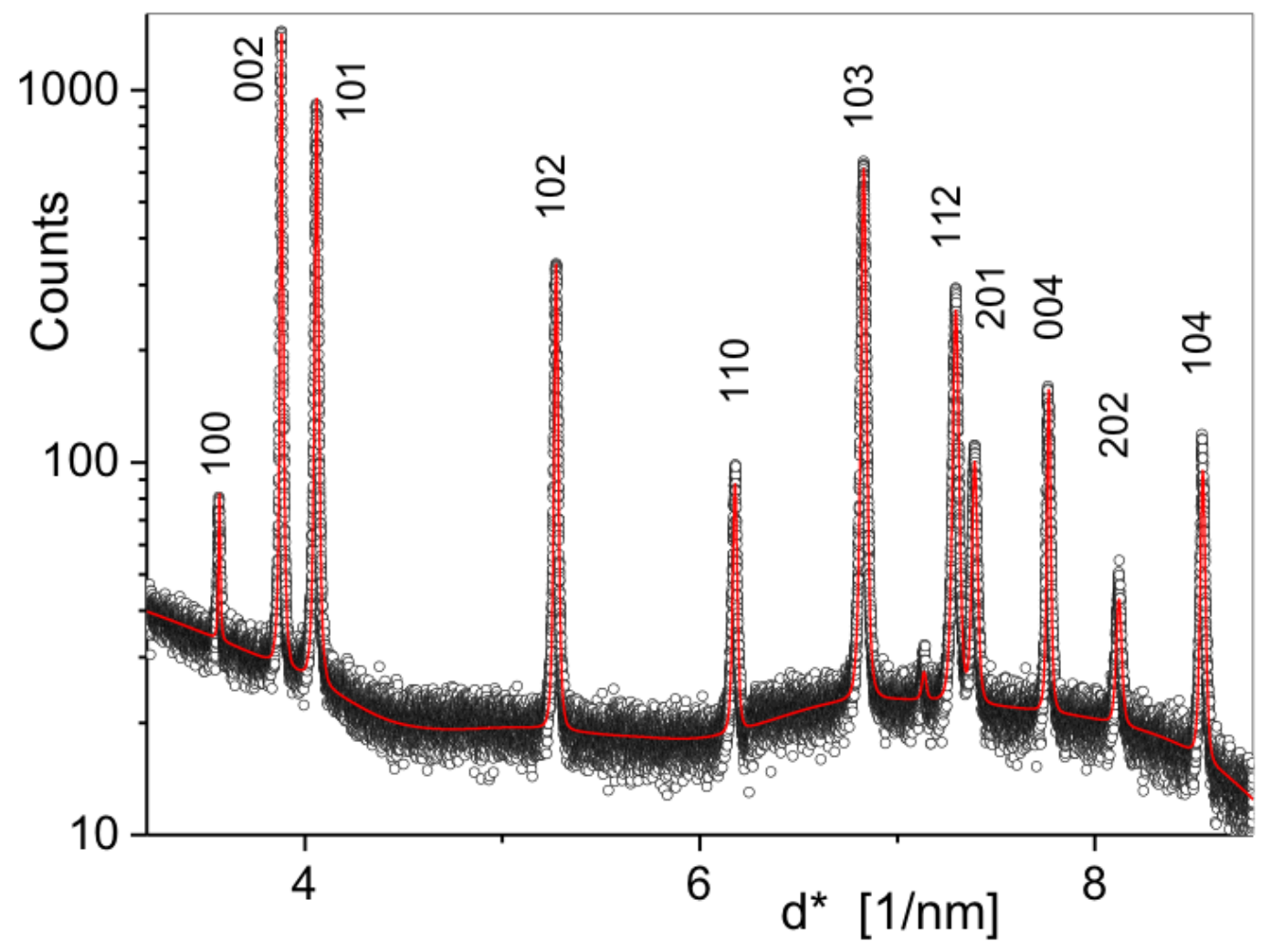

Figure 4(a) shows an example SXRD pattern for the Zr-0.6Fe sample irradiated to 3 dpa during in-situ annealing at $100^{\circ} \mathrm{C}$. At this temperature no change in the full width half maximum (FWHM) was observed from the as-irradiated state. The black data points represent the experimental diffraction pattern and the red line is the theoretical fit of the data generated using CMWP. The largest difference arises from the (0002) peak due to some slight asymmetry towards the base of the experimental peak, which is not captured in the fitted profile.

The diffraction pattern displayed sharp (0002) peaks in the condition that is consistent with what one might expect at such a low dose level, only a-loops are present in this sample. The change in the full width half maximum (FWHM) for the $\{10 \overline{1} 1\}$ peak during the annealing process in the $\mathrm{Zr}-0.6 \mathrm{Fe} 3 \mathrm{dpa}$ sample is plotted in
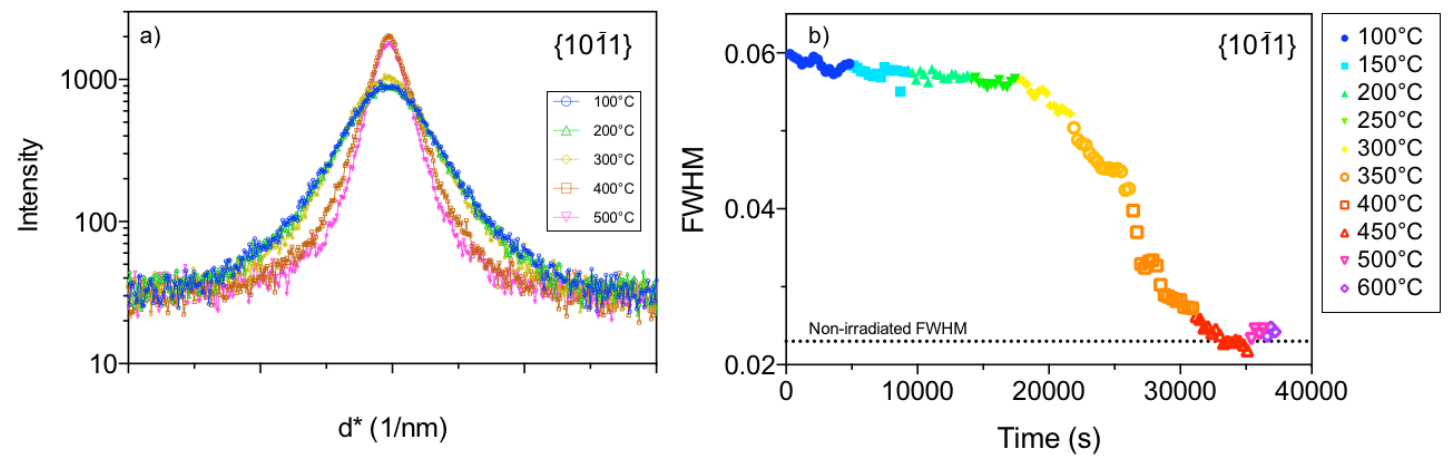
Figure 5 . The $\{10 \overline{1} 1\}$ peak was chosen for study because it is a distinct, high intensity peak with high multiplicity, providing good statistics. The $\{10 \overline{1} 0\}$ peak, being a pure a-component reflection, should exhibit even stronger broadening due to the a-loops but due to the strong texture in the material the intensity of this peak was too low to get reliable results in the current geometry.
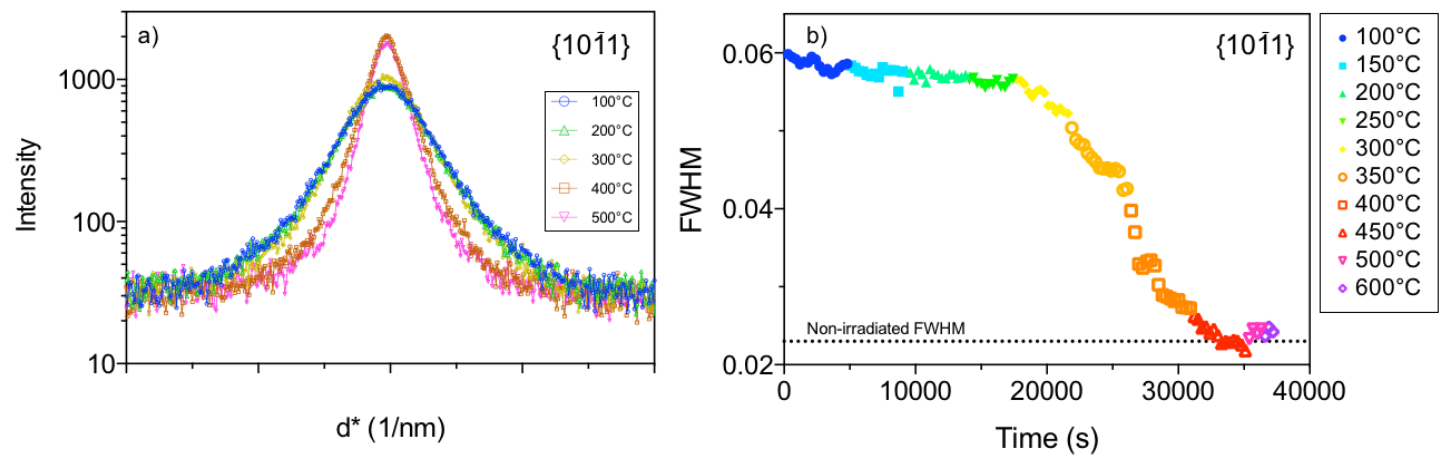

Figure 5 shows little change in the FWHM of the $\{10 \overline{1} 1\}$ peak during the heating process until a temperature of $300^{\circ} \mathrm{C}$ is reached. Beyond $300^{\circ} \mathrm{C}$ the FWHM starts to decrease rapidly. Prior to annealing the FWHM was $0.059^{\circ}$ and at the end of the heating cycle the FWHM was $0.024^{\circ}$. This brings the broadening in line with the nonirradiated $\mathrm{Zr}-0.6 \mathrm{Fe}$ sample, which had a FWHM of $0.023^{\circ}$, indicated by the dashed line in
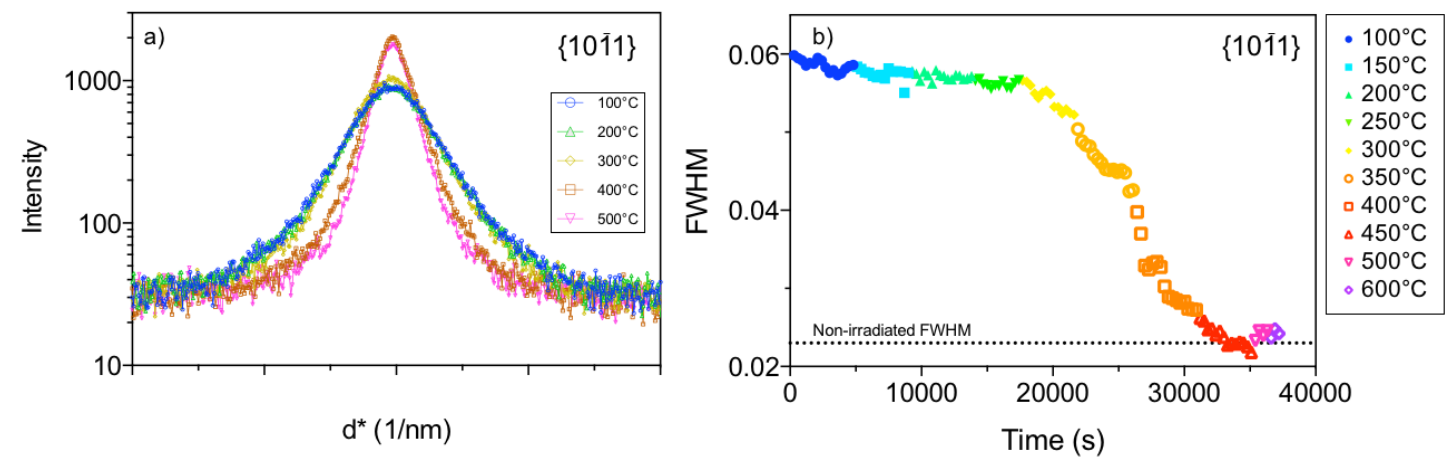

Figure 5. A slight increase in FWHM can be seen from $450^{\circ} \mathrm{C}$ to $500^{\circ} \mathrm{C}$. It is not currently known if this increase corresponds to a microstructural change. 
Dislocation densities were calculated from the diffraction patterns using CMWP and the results are presented in

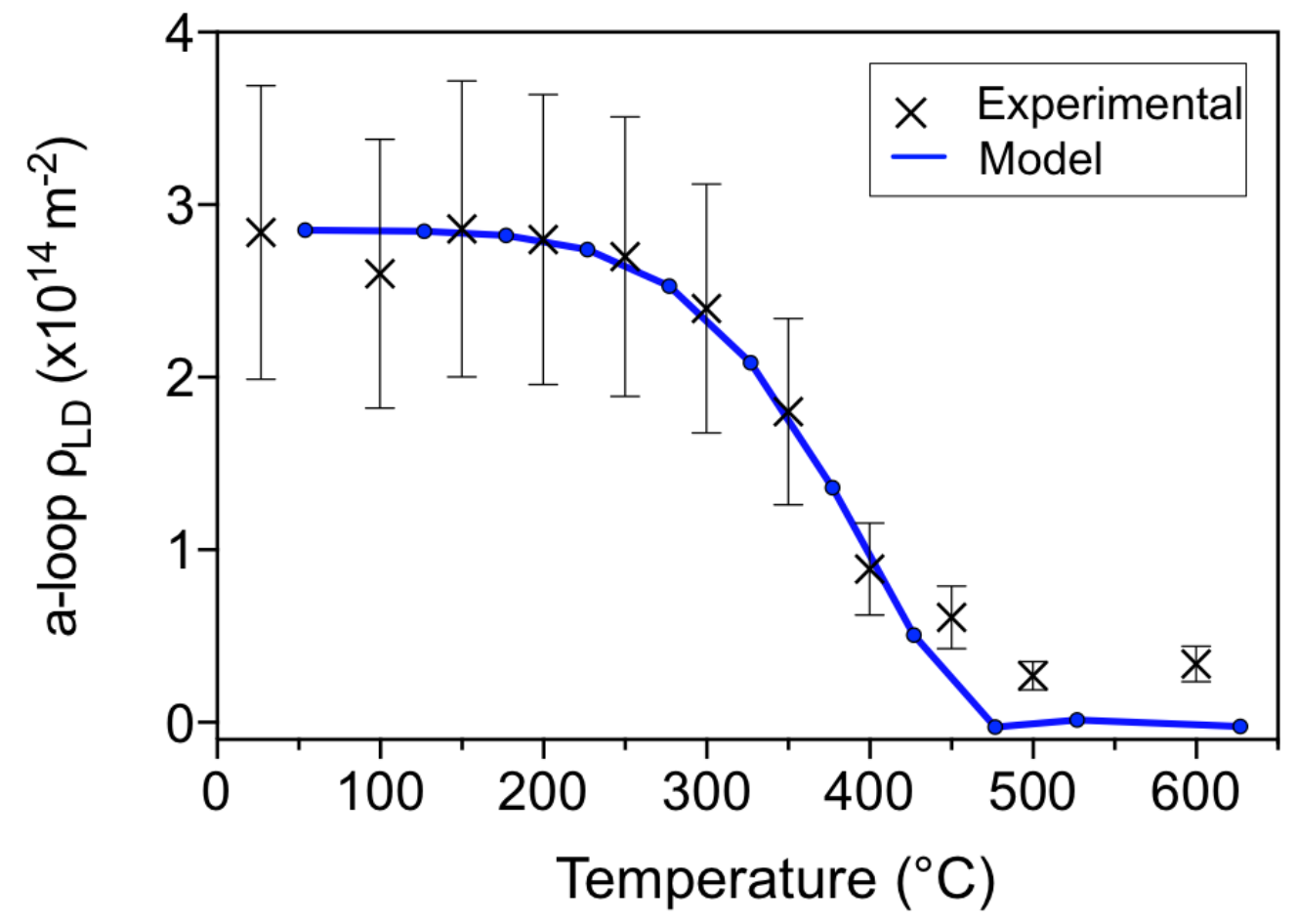

Figure 6. In agreement with the FWHM, a negligible change in dislocation density was observed until $\sim 250{ }^{\circ} \mathrm{C}$ and between $\sim 250$ and $300{ }^{\circ} \mathrm{C}$, the dislocation density begins to decrease reaching a minimum value between $450-500^{\circ} \mathrm{C}$. At this point the dislocation density does not vary significantly up to the final temperature of $600^{\circ} \mathrm{C}$.

\section{$\underline{3.2 \mathrm{In}-\mathrm{situ} \mathrm{TEM} \text { annealing of } \mathrm{Zr}-0.1 \mathrm{Fe} \text { alloy }}$}

In-situ TEM annealing was performed on the $\mathrm{Zr}-0.1 \mathrm{Fe}$ sample that had been protonirradiated to $1.5 \mathrm{dpa}$. Here, the dislocation mobility was monitored as a function of 
temperature by obtaining a BF-STEM image every second.
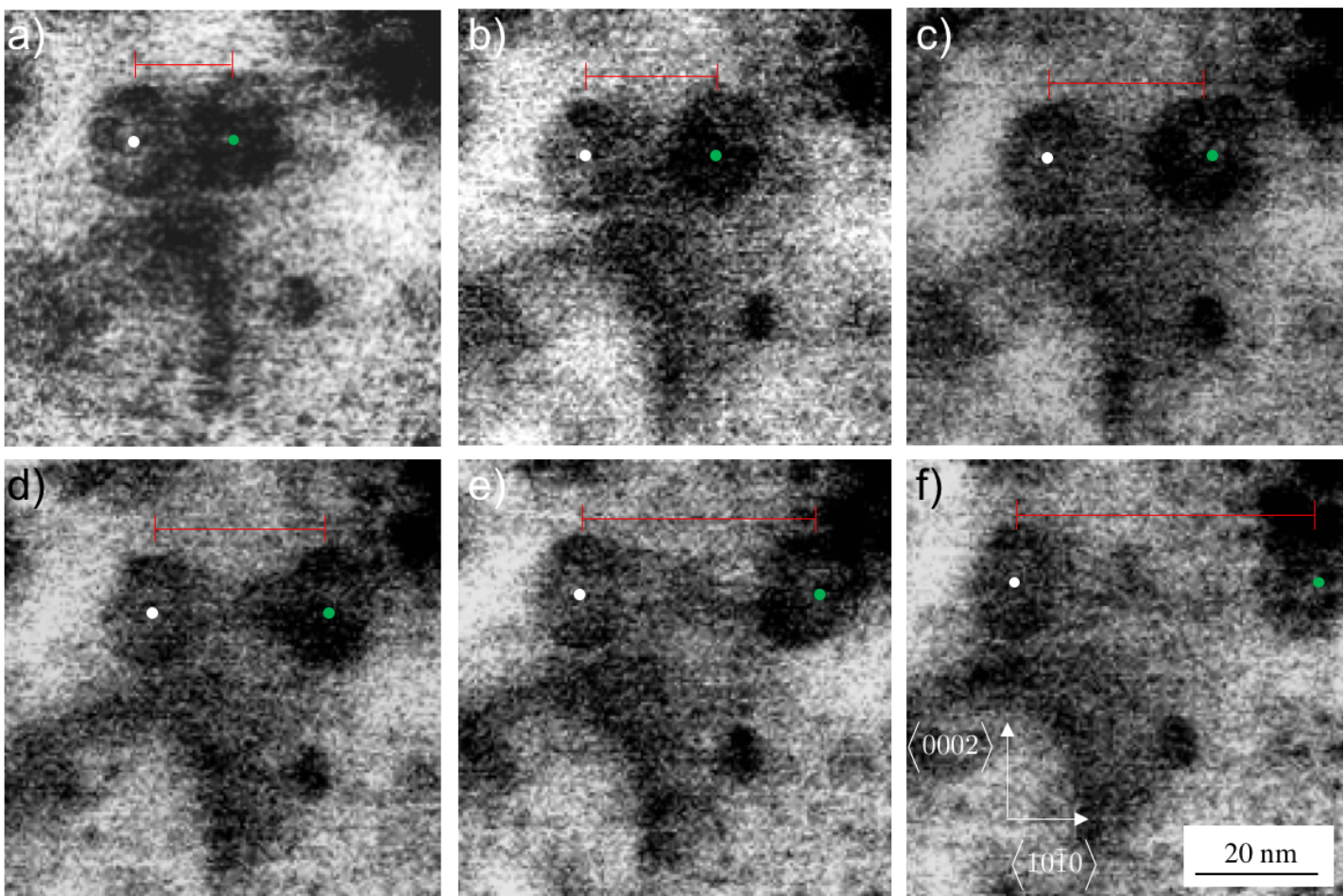

Figure 7(a)-(f) depicts a series of BF-STEM images, taken at the $\langle 11 \overline{2} 0>$ zone axis over 134 seconds, and shows the glide of an a-loop parallel to the trace of the basal plane during annealing at $425^{\circ} \mathrm{C}$. As a BF-STEM image is a $2 \mathrm{D}$ projection of a $3 \mathrm{D}$ sample volume it is not possible to state if the a-loop moves in the $\langle 10 \overline{1} 0\rangle$ or the $\langle 11 \overline{2} 0\rangle$ direction, but it can be observed to move along the trace of the basal plane. However, if one assumes the loop is moving along its glide cylinder, the $\langle 11 \overline{2} 0\rangle$ direction, it either moves toward the foil surface, which would appear in the image as the loop suddenly disappearing, however as the loop moves horizontally in the image the distance the loop travelled can be calculated as $98 \mathrm{~nm}$. Therefore, the rate at which 
the a-loop moves in
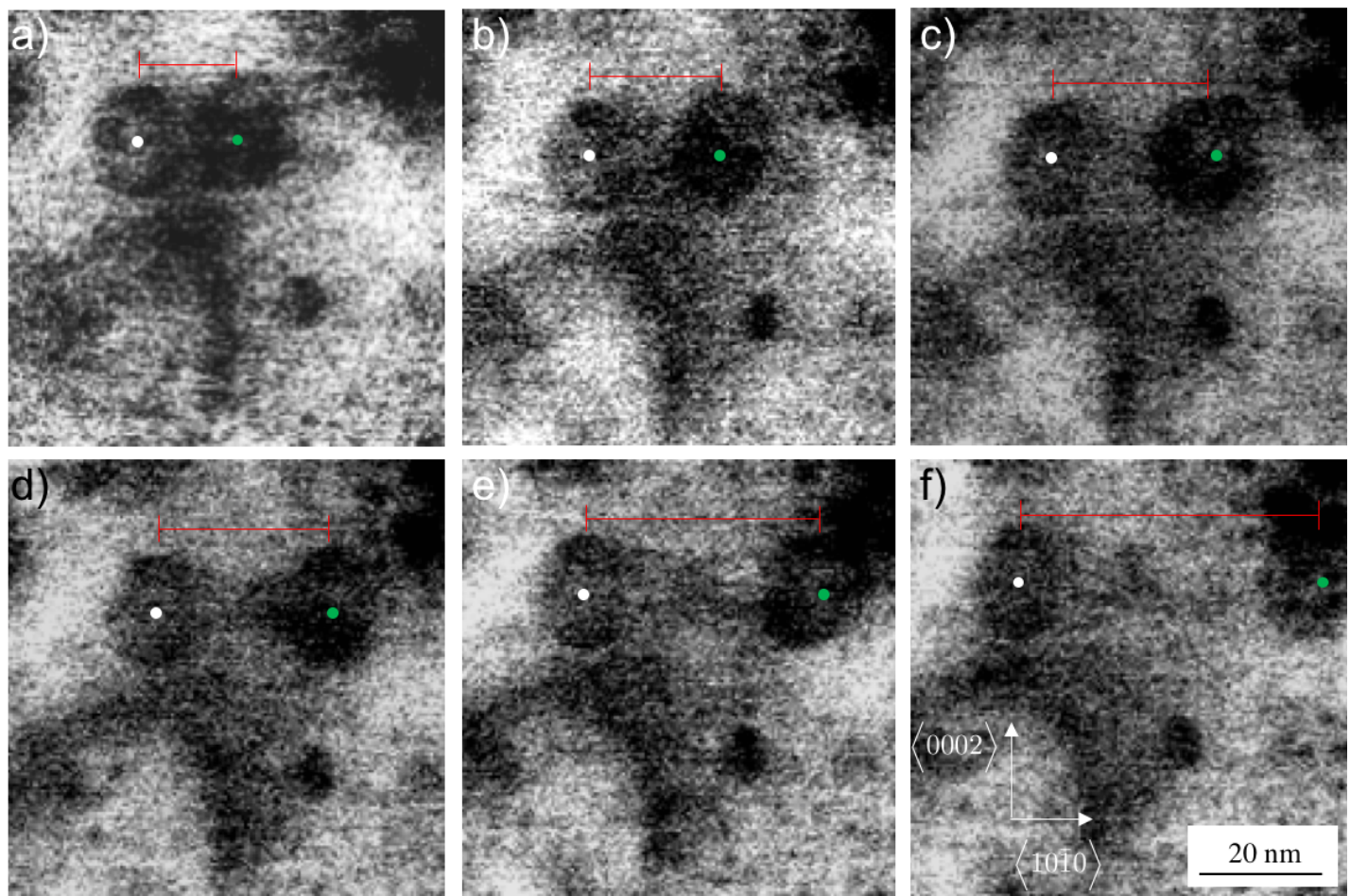

Figure 7 is approximately $7.28 \times 10^{-10} \mathrm{~m} \mathrm{~s}^{-1}$. It must be noted that this is a single example of loop migration as there is a large amount of variation in the speed at which loops annihilate. At no point during the in-situ annealing in the TEM were a-loops observed to move in the c-direction. 


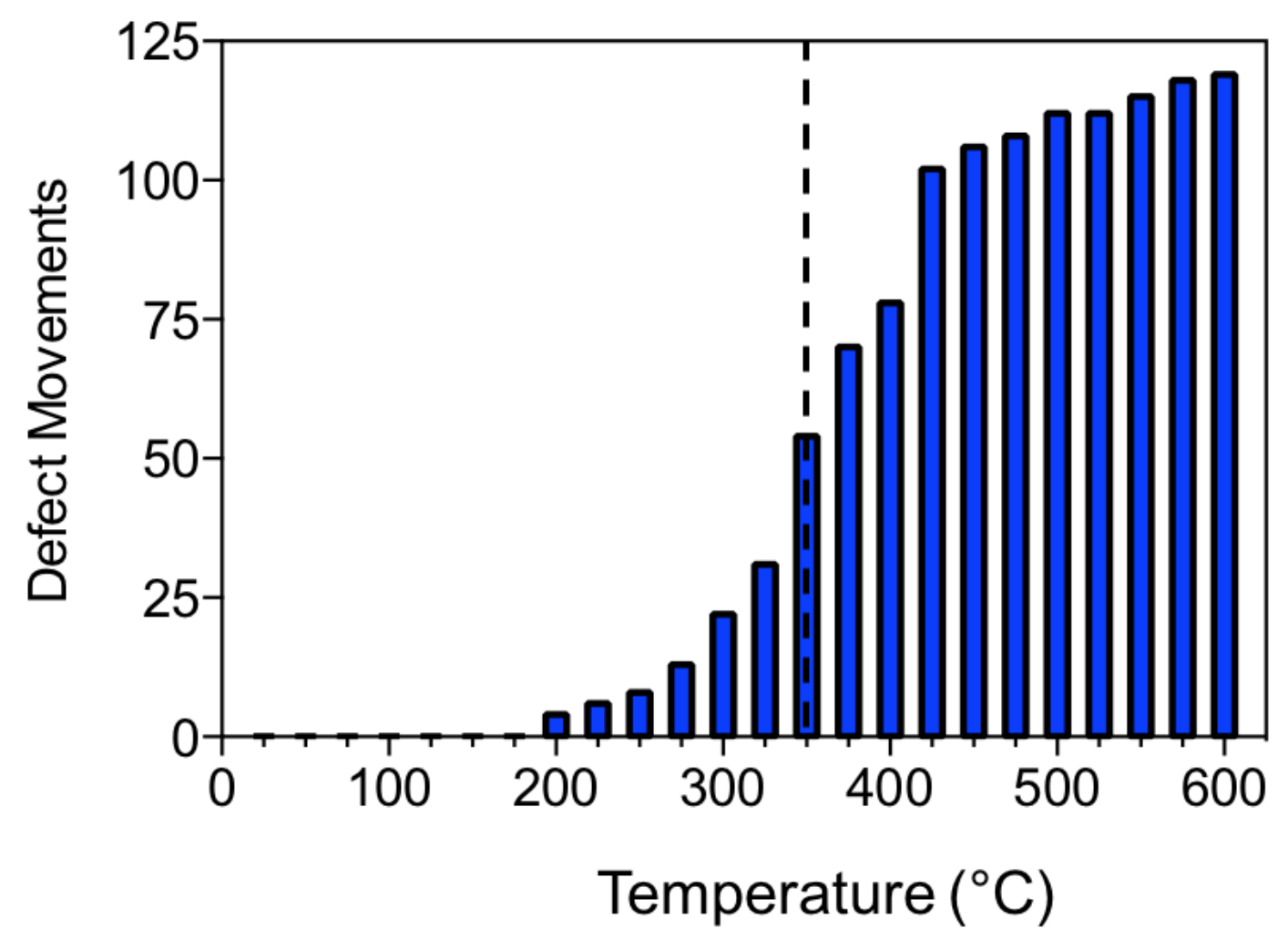

Figure 8 displays the cumulative number of defect movements initiated during the insitu annealing experiment. A defect movement was counted if a dark contrast feature moved in the a-direction or disappeared between consecutive images, signifying either annihilation at the surface or evaporation of a vacancy loop within the sample. No significant changes to the microstructure were observed until the temperature reached $200^{\circ} \mathrm{C}$. At this temperature a-loops started to glide parallel to the trace of the basal plane and annihilate at the surface. Beyond $300^{\circ} \mathrm{C}$, the a-loops began to glide and annihilate at the surface at a faster rate, which continued until $\sim 425^{\circ} \mathrm{C}$, after which the changes became more infrequent until the final temperature of $600^{\circ} \mathrm{C}$. This suggests that $\sim 200$ $300^{\circ} \mathrm{C}$ is the critical temperature required for the annealing process to initiate in a thin foil $\mathrm{Zr}-0.1 \mathrm{Fe}$ sample proton-irradiated to $1.5 \mathrm{dpa}$. Although difficult to interpret quantitatively, this plot demonstrates that the annealing rate is largest between $300^{\circ} \mathrm{C}$ $425^{\circ} \mathrm{C}$. The dashed line indicates the proton-irradiation temperature of $350^{\circ} \mathrm{C}$.

\subsection{Discussion}

In-situ annealing experiments using SXRD have been conducted in order to track the evolution of irradiation-induced dislocation loops during heating. One of the major benefits of in-situ studies is that the sample-to-sample variation, inherent in ex-situ studies, is eliminated during such analysis. It is clear from the plot of FWHM vs. 
time, Figure 5, that once the temperature reaches $300^{\circ} \mathrm{C}$ the peaks begin to sharpen. As the broadening of peaks is primarily due to strain fields associated with dislocations, a change in FWHM is a strong indication of the initiation of the annealing process. For a more quantitative analysis, CMWP was used to provide a detailed assessment of the peak shapes in each diffraction pattern. This allows for the dislocation densities to be obtained as a function of time and annealing temperature. The change in dislocation density during the in-situ annealing experiment is shown in

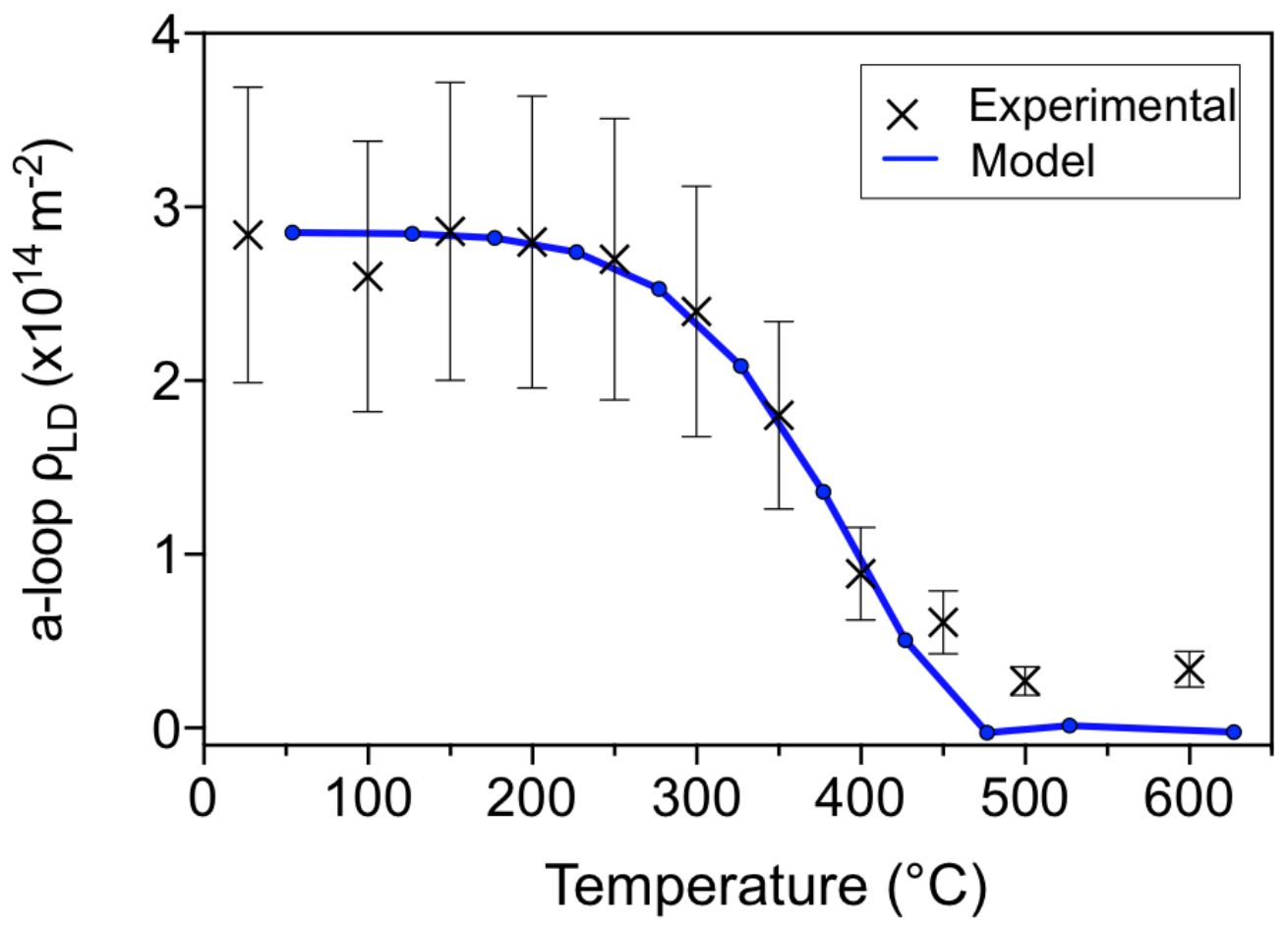

Figure 6. The dislocation density does not begin to drop until the temperature reaches $300^{\circ} \mathrm{C}$ and so it may be concluded that the temperature required to initiate annealing for the $\mathrm{Zr}-0.6 \mathrm{Fe}$ alloy is $250-300^{\circ} \mathrm{C}$. The change in $\mathrm{FWHM}$ with temperature observed for the $1^{\text {st }}$ order pyramidal peak, as seen in
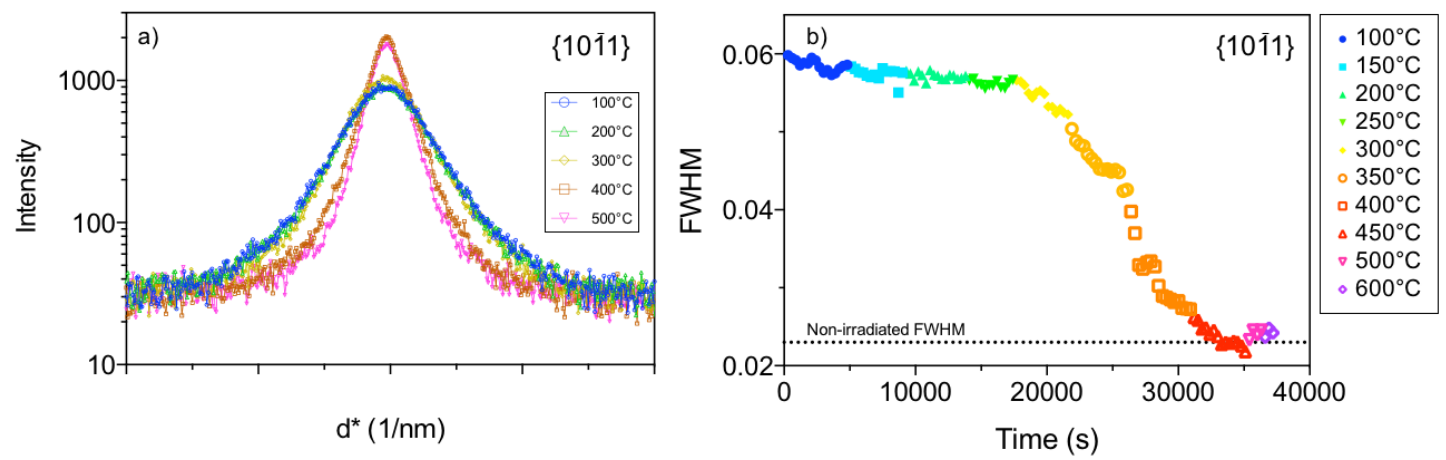

Figure 5, demonstrates that the annealing process is underway at $300^{\circ} \mathrm{C}$ and is essentially complete by $500^{\circ} \mathrm{C}$, when the FWHM values are close to those of the nonirradiated material. 
Interestingly,
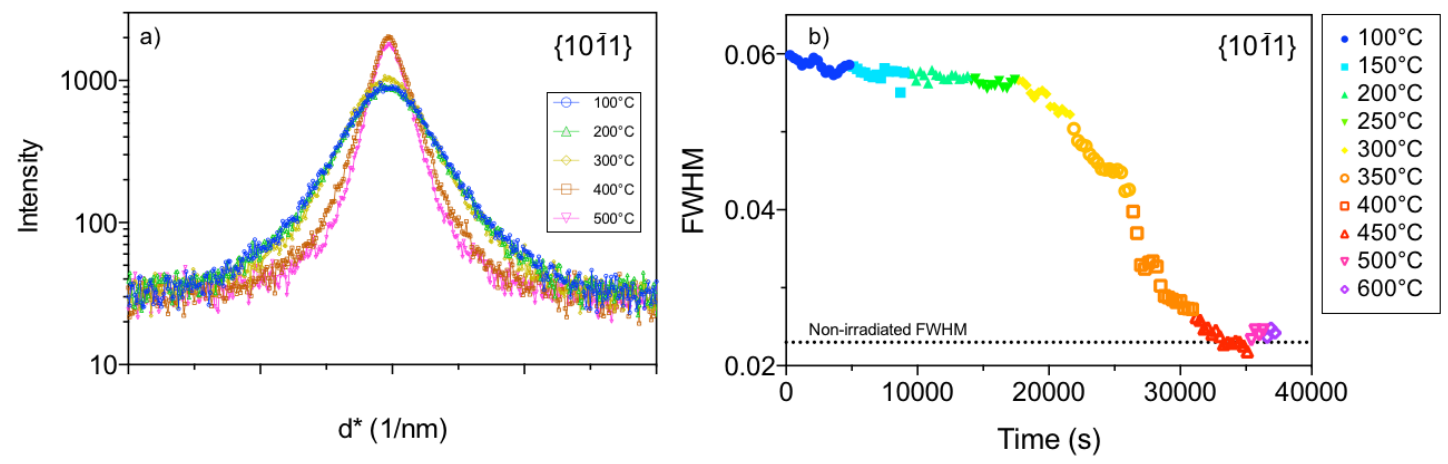

Figure 5 suggests a change in the FWHM when a temperature of $300^{\circ} \mathrm{C}$ was reached, indicating that dislocation structures start to become unstable above this temperature. In contrast, work carried out by Ribis et al. has previously suggested that a temperature of $400^{\circ} \mathrm{C}$ is required to initiate the annealing process [12]. Ribis et al. used a cluster dynamics model to compare the annealing behaviour of neutron-irradiated Zircaloy-2 with experimental data from Adamson and Bell [19], including dislocation densities, loop sizes and hardness values. The sample they investigated was neutron-irradiated to a fluence of up to $6.5 \times 10^{24} \mathrm{n} \mathrm{m}^{-2}(\mathrm{E}>1 \mathrm{MeV})$ at $\sim 327^{\circ} \mathrm{C}$ [19]. Adamson and Bell studied the effect of annealing by heating samples for 1 hour at $400^{\circ} \mathrm{C}-600^{\circ} \mathrm{C}$ in steps of $50^{\circ} \mathrm{C}$. The model proposed by Ribis et al. was able to accurately replicate the experimental results that were obtained using TEM, with respect to the change in loop size and the variation in hardness with annealing temperature. A period of no change was reported in the mean vacancy loop diameter up until $400^{\circ} \mathrm{C}$, after which a dramatic increase in the vacancy loop size was reported with annealing temperatures up to $600^{\circ} \mathrm{C}$. A dramatic decrease was also seen in the hardness at temperatures of $\sim 425^{\circ} \mathrm{C}$. Observations by Ribis et al. and Adamson et al. suggest that a temperature of $\sim 400^{\circ} \mathrm{C}$ is required to activate the annealing process in neutron-irradiated Zircaloy-2. However, lower temperature data, below $400^{\circ} \mathrm{C}$, is missing from the experimental paper, therefore the authors interpolated the trend from the as-irradiated sample to the sample heated to $400^{\circ} \mathrm{C}$ [19]. This lack of low temperature data means that one cannot rule out the possibility that the annealing process begins below $400^{\circ} \mathrm{C}$.

Howe et al. showed that the recovery of the mechanical properties of Zircaloy-2, neutron-irradiated to a fluence of $2.7 \times 10^{24} \mathrm{n} \mathrm{m}^{-2}$ at $280^{\circ} \mathrm{C}$ in the NRX reactor, started at $\sim 300^{\circ} \mathrm{C}[15]$. This experimental data agrees with the observations made in the current study on binary $\mathrm{Zr}-\mathrm{Fe}$ alloys. It is interesting to note that Howe et. al studied the same 
material, irradiated to a similar fluence, as that studied by Adamson et al. [19] yet the temperature required to begin the annealing process differs by $\sim 100^{\circ} \mathrm{C}$. This suggests that the initial irradiation temperature might affect the stability of the dislocations formed. The proton-irradiation in this work was carried out at $350^{\circ} \mathrm{C}$ to offset the higher damage rate in proton-irradiations compared to the damage rate of neutron-irradiation, allowing for diffusional processes to take place [37]. As the temperature required to initiate the annealing process in this work is closer to that found in the work of Howe et al. [15] compared to that of Adamson and Bell [19], in which there are irradiation temperature offsets of $70^{\circ} \mathrm{C}$ and $27^{\circ} \mathrm{C}$, respectively, one might assume that the larger temperature offset more accurately mimics the irradiation-induced defect structures.

As well as SXRD analysis, in-situ annealing in the TEM was also carried out on a 1.5 dpa proton-irradiated $\mathrm{Zr}-0.1 \mathrm{Fe}$ alloy. The annealing process became increasingly rapid as the temperature increased, with the first defect movements being observed at $200^{\circ} \mathrm{C}$, demonstrating that the process is thermally activated. At a temperature range of 300$425^{\circ} \mathrm{C}$ the a-loops were observed to readily glide along prismatic planes and often annihilate at the surface of the foil. It has been proposed previously that coarsening of loops may occur from the direct elastic interaction between adjacent, glissile loops with the same Burgers vector [38], however no evidence for loop coalescence was observed in the region studied during the in-situ heating experiment. At no stage of the annealing process were any observable defects seen to migrate in the c-direction, suggesting that a-loops are only able to move in the direction parallel to the basal plane.

The observed temperature for activation of the annealing process appears to be lower in the TEM than concluded from the SXRD analysis, which can be attributed to three possible explanations. The first is that the thin foil sample geometry in the TEM experiment allows for defects to annihilate at the sample surface. With the glide plane of the loops being close to normal of the foil surface, the dislocation loops have an easy path to two almost perfect sinks. Another issue inherent with thin foil heating experiments is foil bending, as changes in local stress states will have an impact on dislocation mobility. However, no obvious bending was observed in the grain investigated in this work. It is also possible that the difference in initiation temperature between the TEM and SXRD data could be related to the difference in time resolution between the two techniques. It is also possible that the temperature required to initiate 
the observable annealing process between the two techniques, is an artefact of the distance loops have to travel before reaching a sink. For example a loop has a smaller distance to travel in a thin foil sample before they reach a sink compared to in the bulk. During the in-situ SXRD experiment the samples were held for a finite time at each temperature, it is probable that changes in the measured profiles would have become apparent at a lower temperature if held indefinitely.

However, a good agreement for the temperatures required for rapid annealing is observed between the in-situ SXRD and TEM experiments. This observation highlights the strength of using complementary techniques to obtain insight into the behaviour of irradiation-induced defects during heating. The in situ TEM observations provide visual insight into the local behaviour of dislocation loops and allow for small changes to be monitored whereas the in-situ SXRD experiment provides bulk dislocation data averaged over a large number of grains and requires the overall dislocation density to be effected before a change can be observed.

An effective activation energy for the annealing process of a-loops has been calculated to provide a guide for experimental irradiation parameters. An activation energy of $0.46 \mathrm{eV}$ was calculated from the change in a-loop line density during the insitu SXRD experiment

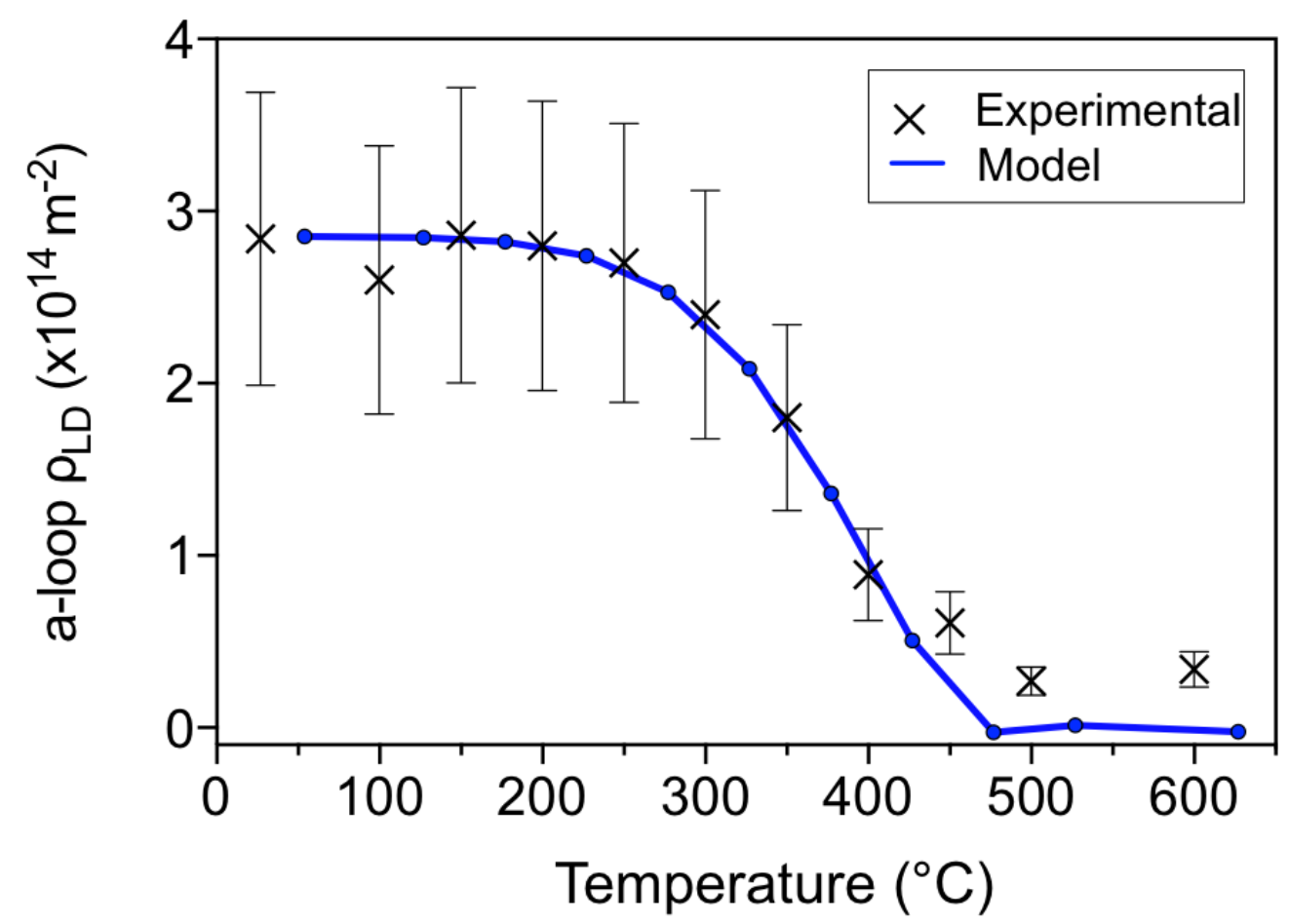


Figure 6). The blue line plotted in

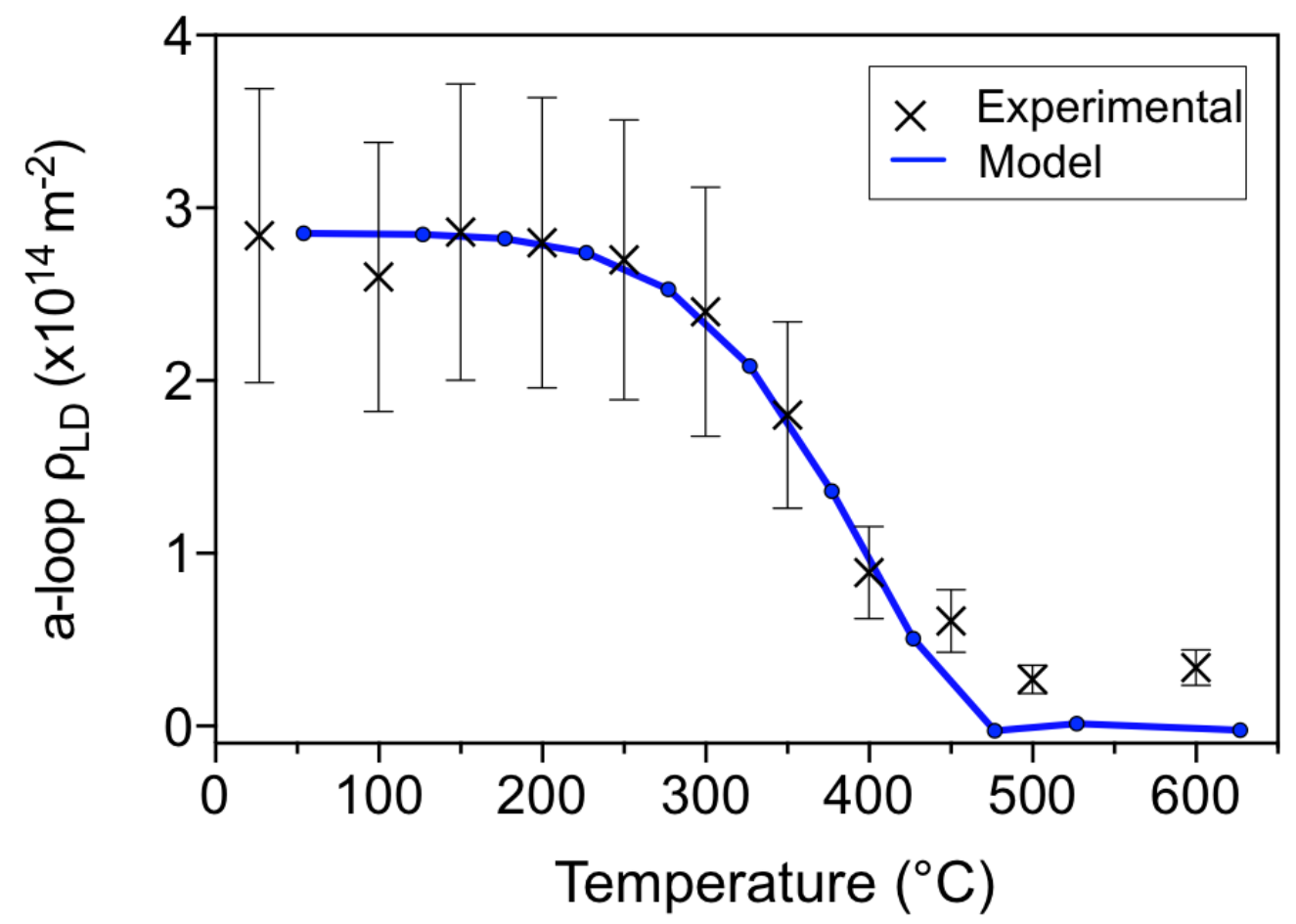

Figure 6 depicts the evolution of line density based on a model used to calculate the effective activation energy assuming Arrhenius behaviour (see supplementary material for the activation energy calculation). It has been previously proposed that the annealing process is due point defects annihilating at the dislocation loops $[39,40]$. Neely used resistivity measurements during an isochronal anneal of electron-irradiated $\mathrm{Zr}$ to investigate the atomic processes occurring at various temperatures [41]. It was shown that at varying temperatures different atomic processes were occurring and that the migration of a given point defect can have different activation energies depending on the length of the diffusion path or the strength of a sink. The activation energy calculated in this present study, $0.46 \mathrm{eV}$, falls in-between the values of the different annealing stages involving self-interstitial migration, calculated experimentally by Neely, 0.26 and $0.57 \mathrm{eV}$ [41]. However, Christien and Barbu state the migration energy of self-interstitials to be between $0.06-0.15 \mathrm{eV}$ for the a- and c- axis, respectively, based on a cluster dynamic model and the migration energy of vacancies was found to be 0.93 $\mathrm{eV}$ [42]. Yet, it has been shown through computer simulations that SIA do not remain in the matrix with a significant concentration [43]. The formation energy of point defects is much higher than the activation energy calculated in this work, 1.79 and 3.77 $\mathrm{eV}$ for vacancy and SIAs, respectively [44]. Due to the high formation energy of point 
defects it can be assumed that SIAs do not play a significant role in the annealing process of dislocation loops.

Previous theories describing the annealing behaviour of dislocation loops assume that vacancy diffusion is the controlling aspect $[12,45]$. This is backed up by the experimental observation that only large vacancy loops remain after post-irradiation heat treatment [12]. As the activation energy calculated from this work is lower than the modelled energy for migration of vacancies, it is possible there are multiple events by which dislocation loops can anneal. The possibility of dislocation loops gliding to sinks should not be dismissed, nor should the possibility of enhanced point defect diffusion based on proximity to a dislocation as well as the effects of microchemical changes in the matrix. Recent atomistic modelling work has found that during the annealing of irradiated copper, point defect formation energy is much lower at grain boundaries than in the bulk [46]. Further modelling of this complex phenomenon is required for a complete understanding of the mechanism.

It should be highlighted that the fit based on the model in

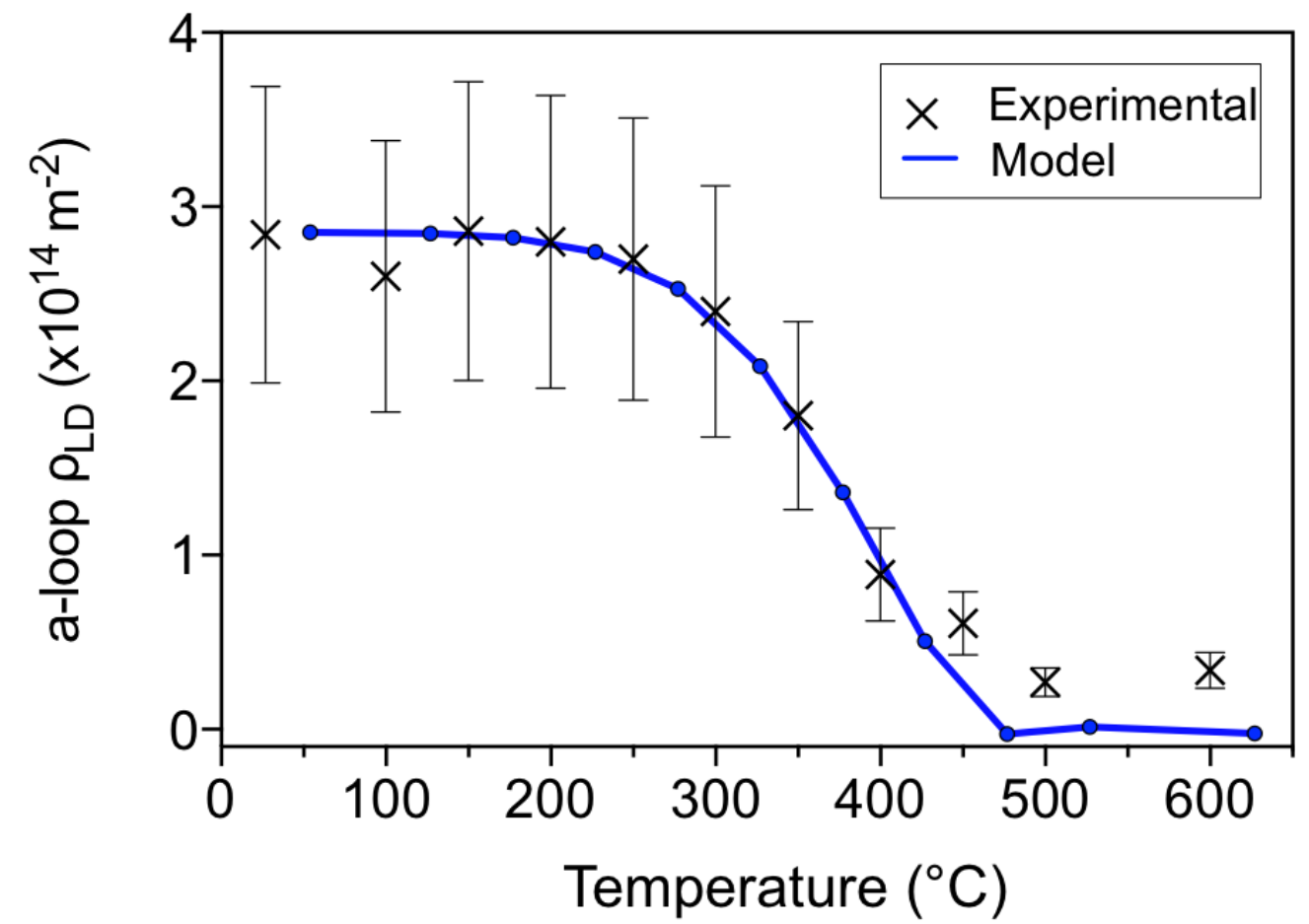

Figure 6 deviates from the experimental data after $\sim 400^{\circ} \mathrm{C}$. This may indicate a more complex mechanism varying over the temperature range. For example, this difference in behaviour may indicate a transition to a new mechanism and therefore a second 
activation energy may be dominant above $400^{\circ} \mathrm{C}$. This could be explained by the formation of meta-stable irradiation damage during irradiation, yielding features that are eliminated by the initial annealing process. However, in this experiment there are not enough data points after $400^{\circ} \mathrm{C}$ to accurately investigate this possibility.

Using the activation energy calculated as part of this work it is possible to predict the temperature increase needed to change the annealing rate by a given factor. Assuming an activated process with a rate, $\Gamma$;

$$
\Gamma=e^{-\frac{E_{A}}{k T}}
$$

Where $E_{A}$ is the activation energy and $T$ the temperature then we can calculate the temperature $T_{1}$ required for a given fractional increase in rate $\Gamma_{1} / \Gamma_{0}$ from a reference rate $\Gamma_{0}$ and $\mathrm{T}_{0}$ from,

$$
\frac{1}{T_{1}}=\frac{1}{T_{0}}-\frac{k_{B}}{E_{A}} \ln \left(\frac{\Gamma_{1}}{\Gamma_{0}}\right)
$$

For example, to double the rate $\left(\Gamma_{1} / \Gamma_{2}=2\right)$ from a reference temperature of $\mathrm{T}_{0}=300^{\circ} \mathrm{C}$ requires a temperature increment of $\mathrm{T}_{1}-\mathrm{T}_{0}=50.8^{\circ} \mathrm{C}$.

The activation energy calculated here could also be used in further understanding the relationship between the simultaneous formation and annealing of irradiation-induced defects during proton-irradiations. This notion was discussed by Motta et al. whilst studying the amorphisation behaviour of $\mathrm{Zr}_{3} \mathrm{Fe}$ during electron irradiation [47]. This phenomenon can be thought of as the point defects being frozen in place at low irradiation temperatures, whilst at higher irradiation temperatures the damage rate is offset by the competing process of annealing point defects. Motta et al. observed this phenomenon through changes in the amorphisation behaviour of the $\mathrm{Zr}_{3} \mathrm{Fe}$ phase; at low irradiation temperatures the dose required to initiate the amorphisation transformation was lower than that for higher irradiation temperature electronirradiations [47]. The presence of irradiation-induced chemical segregation or precipitation may also influence the stability of dislocations. Ribis et al. studied the effect of annealing on a $\mathrm{Zr}-1.0 \mathrm{Nb}-0.02 \mathrm{Fe}-1.4 \mathrm{O} \mathrm{wt} \%$ alloy and found that after 960 hours at $450^{\circ} \mathrm{C}$ the hardness had not fully recovered to the value of the non-irradiated specimen [12]. It was suggested that this increased hardness was due to irradiation- 
induced $\beta-\mathrm{Nb}$ precipitates in the sample that did not dissolve at the annealing temperature [48]. This irradiation-induced precipitation may provide barriers to dislocation loop glide and therefore increase the stability of the dislocation structure compared to alloys that show little irradiation-induced precipitation. This phenomenon may explain the lower temperature required for annealing in the $\mathrm{Zr}-0.1 \mathrm{Fe}$ sample studied here, where we do not have such precipitates away from the sparsely distributed SPPs, compared to neutron-irradiated Zircaloy- 2 where irradiation-induced clustering has been observed throughout the matrix $[20,21,49]$.

Further in-situ experiments on alloys irradiated at various temperatures with different chemical compositions are required to better understand the annealing behaviour, as evidence suggests that varying the alloy composition and the initial irradiation temperature can have a significant effect on the stability of the irradiation-induced dislocation structures. From the results presented here, it is clear that in-situ experiments combining SXRD and TEM can provide reliable information regarding temperatures for the onset of loop annihilation and the rates at which this process occurs. A particular benefit of this approach is that any sample-to-sample variation is eliminated during such in-situ analysis, compared to ex-situ studies.

\section{Conclusions}

In-situ annealing experiments have been carried out on proton-irradiated $\mathrm{Zr}-\mathrm{Fe}$ binary alloys to gain a better understanding about the thermal stability of irradiation-induced damage. This work highlights the benefits of carrying out in situ experiments and utilises modern techniques to provide vital information on the annealing behaviour of irradiated $\mathrm{Zr}$ alloys. The following conclusions can be drawn:

- In-situ annealing experiments using SXRD on irradiated $\mathrm{Zr}$ alloys have enabled subtle changes in the diffraction peak shapes to be tracked, and for changes in dislocation densities in a statistically significant volume of material to be inferred.

- In-situ TEM heating experiments provide information complementary to the SXRD analysis through a real-time evaluation of localised loop mobility during annealing. 
- Both in-situ SXRD and TEM annealing experiments show that the dislocation structure, consisting solely of a-loops, in 1.5 and 3 dpa proton-irradiated $\mathrm{Zr}-\mathrm{Fe}$ binary alloys irradiated at $350^{\circ} \mathrm{C}$, begins to anneal at $275-300^{\circ} \mathrm{C}$, with the majority of the annealing process taking place between $300-450^{\circ} \mathrm{C}$.

- An effective activation energy for the annealing process of $0.46 \mathrm{eV}$ has been calculated from the in-situ SXRD data.

- TEM observations have shown that a-loops glide purely along prismatic planes during annealing in a thin foil specimen, with no indication of migration in the c-direction.

\section{Acknowledgements}

This work was funded by an EPSRC Leadership Fellowship for the study of irradiation damage in zirconium alloys [EP/I005420/1], with additional industrial contributions from National Nuclear Laboratory. The authors would like to thank Gary Was and Ovidui Toader for their advice and use of the Michigan Ion Beam Laboratory. The authors would also like to express their gratitude to Stephen Thompson for assistance in using the I11 beamline at Diamond Light Source. Finally the authors would like to thank Dr Sarah Haigh and Alex Rakowski for assistance using the Aduro in situ heating holder. Please note that original images and diffraction data from this work can be made available on request.

\section{References}

[1] L. Hallstadius, S. Johnson, E. Lahoda, Cladding for High Performance Fuel, Prog. Nucl. Energy. 57 (2012) 71-76.

[2] C.H. Woo, Defect Accumulation Behaviour in HCP Metals and Alloys, J. Nucl. Mater. 276 (2000) 90-103.

[3] R.B. Adamson, Effects of Neutron Irradiation on Microstructure and Properties of Zircaloy, in: Zircon. Nucl. Ind. Twelfth Int. Symp., 2000: pp. 15-31.

[4] V. Fidleris, R.P. Tucker, R.B. Adamson, An Overview of Microstructural and Experimental Factors That Affect the Irradiation Growth Behavior of Zirconium Alloys, in: Zircon. Nucl. Ind. Seventh Int. Symp., 1987: pp. 49-85.

[5] M. Griffiths, A Review of Microstructure Evolution in Zirconium Alloys During Irradiation, J. Nucl. Mater. 159 (1988) 190-218.

[6] F. Onimus, J.L. Bechade, Radiation Effects in Zirconium Alloys, Compr. Nucl. Mater. 4 (2012) 273-246. 
[7] A. Jostsons, P.M. Kelly, R.G. Blake, The Nature of Dislocation Loops in Neutron Irradiated Zirconium, J. Nucl. Mater. 66 (1977) 236-256.

[8] M. Griffiths, R.W. Gilbert, V. Fidleris, Accelerated Irradiation Growth of Zirconium Alloys, Zircon. Nucl. Ind. Eighth Int. Symp. (1989) 658-677.

[9] R.A. Holt, R.W. Gilbert, c-Component Dislocations in Annealed Zircaloy Irradiated at about 570K, J. Nucl. Mater. 137 (1986) 185-189.

[10] L. Tournadre, F. Onimus, J.L. Béchade, D. Gilbon, J.M. Cloué, J.P. Mardon, X. Feaugas, O. Toader, C. Bachelet, Experimental Study of the Nucleation and Growth of c-Component Loops Under Charged Particle Irradiations of Recrystallized Zircaloy-4, J. Nucl. Mater. 425 (2012) 76-82.

[11] F. Onimus, I. Monnet, J.L. Béchade, C. Prioul, P. Pilvin, A Statistical TEM Investigation of Dislocation Channeling Mechanism in Neutron Irradiated Zirconium Alloys, J. Nucl. Mater. 328 (2004) 165-179.

[12] J. Ribis, F. Onimus, J.L. Béchade, S. Doriot, A. Barbu, C. Cappelaere, C. Lemaignan, Experimental Study and Numerical Modelling of the Irradiation Damage Recovery in Zirconium Alloys, J. Nucl. Mater. 403 (2010) 135-146.

[13] T. Yasuda, M. Nakatsuka, K. Yamashita, Deformation and Fracture Properties of Neutron-Irradiated Recrystallized Zry-2 Cladding Under Uniaxial Tension, Zircon. Nucl. Ind. Seventh Int. Symp. 939 (1987) 734-747.

[14] T. Torimaru, T. Yasuda, M. Nakatsuka, Changes in Mechanical Properties of Irradiated Zircaloy-2 Fuel Cladding Due to Short Term Annealing, J. Nucl. Mater. 238 (1996) 169-174.

[15] L.M. Howe, W.R. Thomas, The Effect of Neutron Irradiation on the Tensile Properties of Zircaloy-2, J. Nucl. Mater. (1960) 248-260.

[16] H.R. Higgy, F.H. Hammad, Effect of Neutron Irradiation on the Tensile Properties of Zircaloy-2 and Zircaloy-4, J. Nucl. Mater. 44 (1972) 215-227.

[17] P. V. Fedotov, L.P. Loshmanov, A. V. Kostyukhina, Recovery of the Mechanical Properties of an Irradiated E110 Alloy, Russ. Metall. 2014 (2014) $762-767$.

[18] F. Onimus, Investigation of Neutron Radiation Effects on the Mechanical Behavior of Recrystallized Zirconium Alloys, J. Nucl. Mater. 358 (2006) 176189.

[19] R.B. Adamson, W.L. Bell, Effects of Neutron Irradiation and Oxygen Content on the Microstructure and Mechanical Properties of Zircaloy, in: Microstrcture Mech. Behav. Mater., 1985.

[20] M. Topping, A. Harte, P. Frankel, G. Sundell, M. Thuvander, H.O. Andrenn, D. Jadernas, P. Tejland, J. Romero, E.C. Darby, S. Dumbill, L. Hallstadius, M. Preuss, The Effect of Iron on Dislocation Evolution in Model and Commercial Zirconium Alloys, Zircon. Nucl. Ind. Eighteenth Int. Symp. (2016) Waiting publication. 
[21] A. Harte, M. Topping, P. Frankel, D. Jädernäs, J. Romero, L. Hallstadius, E.C. Darby, M.Preuss, Nano-Scale Chemical Evolution in a Proton- and NeutronIrradiated Zr Alloy, J. Nucl. Mater. 487 (2017) 30-42.

[22] A. Harte, D. Jädernäs, M. Topping, P. Frankel, C.P. Race, J. Romero, L. Hallstadius, E.C. Darby, M. Preuss, The Effect of Matrix Chemistry on Dislocation Evolution in an Irradiated Zr Alloy, Acta Mater. 130 (2017) 69-82.

[23] A. Rogerson, R.H. Zee, Irradiation Growth in Zirconium-Tin Alloys at 353 and 553K, J. Mater. Res. 152 (1988) 220-224.

[24] L. Balogh, D.W. Brown, P. Mosbrucker, F. Long, M.R. Daymond, Dislocation Structure Evolution Induced by Irradiation and Plastic Deformation in the $\mathrm{Zr}$ 2.5Nb Nuclear Structural Material Determined by Neutron Diffraction Line Profile Analysis, Acta Mater. 60 (2012) 5567-5577.

[25] T. Seymour, P. Frankel, L. Balogh, T. Ungár, S.P. Thompson, D. Jadernas, J. Romero, L. Hallstadius, M.R. Daymond, G. Ribárik, M. Preuss, Evolution of Dislocation Structure in Neutron Irradiated Zircaloy-2 Studied by Synchrotron X-ray Diffraction Peak Profile Analysis, Acta Mater. 126 (2017) 102-113.

[26] E. Tenckhoff, Review of Deformation Mechanisms , Texture , and Mechanical Anisotropy in Zirconium and Zirconium Base Alloys, J. ASTM Int. 2 (2011) $25-50$.

[27] R.E. Stoller, M.B. Toloczko, G.S. Was, A.G. Certain, S. Dwaraknath, F.A. Garner, On the Use of SRIM for Computing Radiation Damage Exposure, Nucl. Instruments Methods Phys. Res. B. 310 (2013) 75-80.

[28] S.P. Thompson, J.E. Parker, J. Potter, T.P. Hill, A. Birt, T.M. Cobb, F. Yuan, C.C. Tang, Beamline I11 at Diamond: a new instrument for high resolution powder diffraction., Rev. Sci. Instrum. 80 (2009) 75107.

[29] G. Ribárik, T. Ungár, J. Gubicza, MWP-fit : a Program for Multiple WholeProfile Fitting of Diffraction Peak Profiles by ab initio Theoretical Functions, J. Appl. Crystallogr. (2001) 669-676.

[30] G. Ribárik, J. Gubicza, T. Ungár, Correlation Between Strength and Microstructure of Ball-Milled Al-Mg Alloys Determined by X-ray Diffraction, Mater. Sci. Eng. A. 387-389 (2004) 343-347.

[31] T. Ungár, J. Gubicza, G. Ribárik, A. Borbély, Crystallite Size Distribution and Dislocation Structure Determined by Diffraction Profile Analysis : Principles and Practical Application to Cubic and Hexagonal Crystals Research Papers, J. Appl. Crystallogr. 34 (2001) 298-310.

[32] L. Balogh, G. Ribárik, T. Ungár, Stacking Faults and Twin Boundaries in FCC Crystals Determined by X-Ray Diffraction Profile Analysis, J. Appl. Phys. 100 (2006) 23512.

[33] L. Balogh, G. Tichy, T. Ungár, Twinning on Pyramidal Planes in Hexagonal Close Packed Crystals Determined Along with Other Defects by X-Ray Line Profile Analysis, J. Appl. Crystallogr. 42 (2009) 580-591. 
[34] M.A. Krivoglaz, Theory of X-Ray and Thermal Neutron Scattering by Real Crystals, Plenum Press, New York, 1969.

[35] M.A. Krivoglaz, X-Ray and Neutron Diffraction in Non Ideal Crystals, Springer-Verlag, Berlin, 1996.

[36] M. Wilkens, The Determination of Density and Distribution of Dislocations in Deformed Single Crystals from Broadened X-Ray Diffraction Profiles, Phys. Status Solidi A. 359 (1970) 359-370.

[37] G.S. Was, Fundamentals of Radiation Materials Science, Springer, Berlin, 2007.

[38] B. Burton, M. V. Speight, The Coarsening and Annihilation Kinetics of Dislocation LoopS, Philos. Mag. A. 53 (1986) 385-402.

[39] A.K. Khan, Z. Yao, M.R. Daymond, R.A. Holt, Effect of Foil Orientation on Damage Accumulation During Irradiation in Magnesium and Annealing Response of Dislocation Loops, J. Nucl. Mater. 423 (2012) 132-141.

[40] P. Mukherjee, P.M.G. Nambissan, P. Sen, P. Barat, S.K. Bandyopadhyay, Proton Irradiation Effects in Zr-1.0 Nb-1.0 Sn-0.1 Fe Probed by Positron Annihilation, J. Nucl. Mater. 273 (1999) 338-342.

[41] H.H. Neely, Damage Rate and Recovery Measurements on Zirconium After Electron Irradiation at Low Temperatures, Radiat. Eff. 3 (1970) 189-201.

[42] F. Christien, A. Barbu, Effect of Self-Interstitial Diffusion Anisotropy in Electron-Irradiated Zirconium : A Cluster Dynamics Modeling, J. Nucl. Mater. 346 (2005) 272-281.

[43] F. Christien, A. Barbu, Cluster Dynamics Modelling of Irradiation Growth of Zirconium Single Crystals, J. Nucl. Mater. 393 (2009) 153-161.

[44] G.J. Ackland, S.J. Wooding, D.J. Bacon, Defect, Surface and DisplacementThreshold Properties of $\alpha$-Zirconium Simulated with a Many-Body Potential, Philos. Mag. A. 71 (1995) 553-565.

[45] F. Kroupa, J. Silcox, M.J. Whelan, On the Annealing of Prismatic Dislocation Loops in Aluminum, Philos. Mag. 68 (1961) 971.

[46] X. Bai, A. Voter, R.G. Hoagland, M. Nastasi, B.P. Uberuaga, Efficient Annealing of Radiation Damage Near Grain Boundaries via, Science (80-. ). 327 (2010) 1631-1635.

[47] A.T. Motta, L.M. Howe, P.R. Okamoto, Amorphization Kinetics of Zr3Fe Under Electron Irradiation, J. Nucl. Mater. 205 (1993) 258-266.

[48] D. Gilbon, A. Somiak, S. Doriot, J. Mardon, Irradiation Creep and Growth Behavior and Microstructural Evolution of Advanced Zr-Base Alloys, in: Zircon. Nucl. Ind. Twelfth Int. Symp., 2000: pp. 51-73.

[49] G. Sundell, M. Thuvander, P. Tejland, M. Dahlback, L. Hallstadius, H.O. Andrenn, Redistribution of Alloying Elements in Zircaloy-2 After In-Reactor 
Exposure, J. Nucl. Mater. 454 (2014) 178-185.

Figures

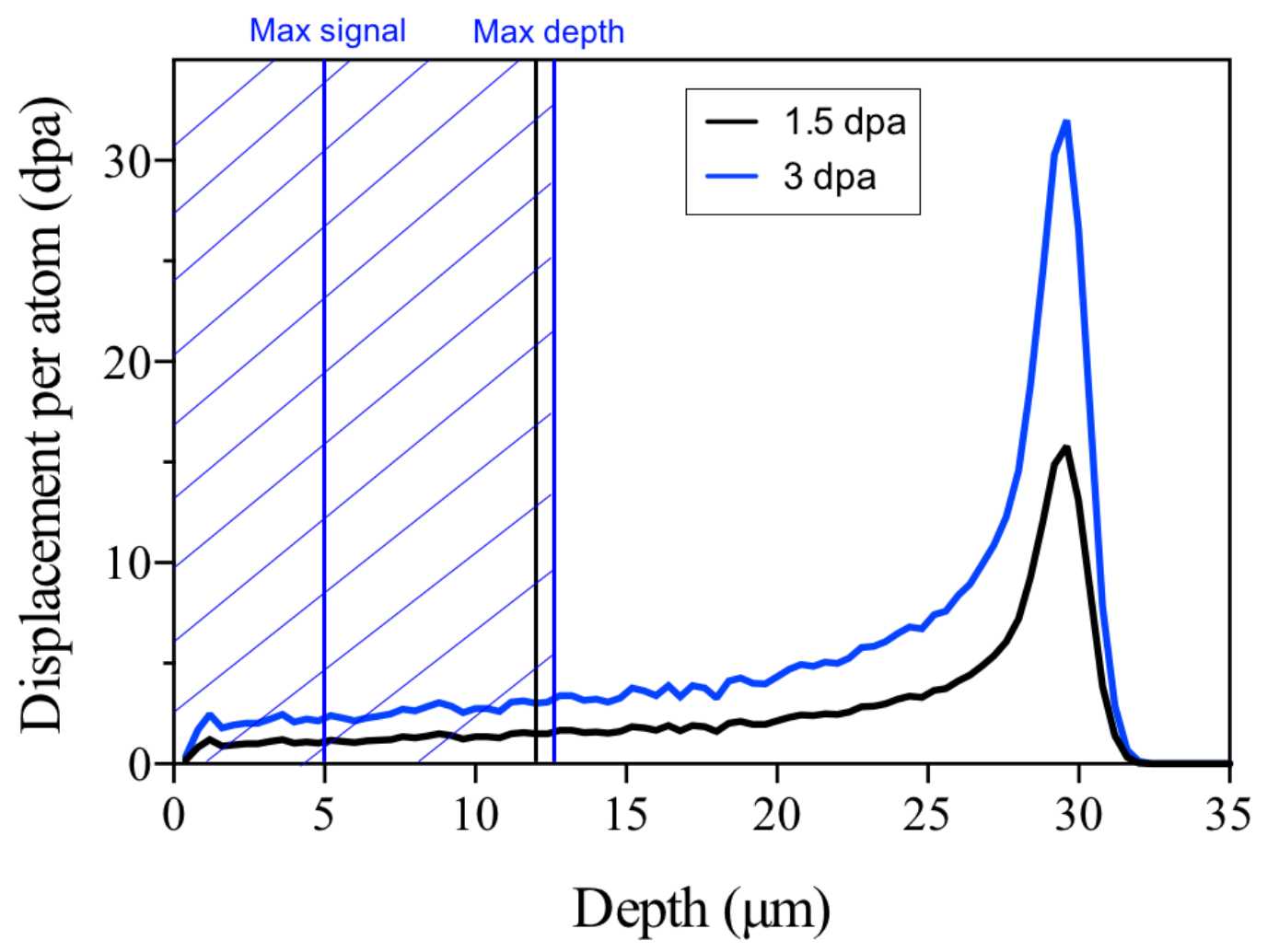


Figure 1. Damage profiles generated using SRIM for pure Zr calculated using the "Quick" method. The simulation was carried out using $2 \mathrm{MeV}$ protons and a displacement threshold energy of $40 \mathrm{eV}$ for $\mathrm{Zr}$. The calculation of dpa was carried out assuming a constant current density of $0.2 \mu \mathrm{A} \mathrm{mm} \mathrm{mm}^{-2}$ with a damage rate of $1.3 \times 10^{-5} \mathrm{dpa} \mathrm{s}^{-1}$. The black vertical line represents the region studied using TEM ( 12 $\mu \mathrm{m}$ from the sample surface), and the blue hatched area represents the region studied via SXRD. The maximum penetration of the X-rays and the depth from which the maximum intensities of diffracted X-rays originate are indicated.

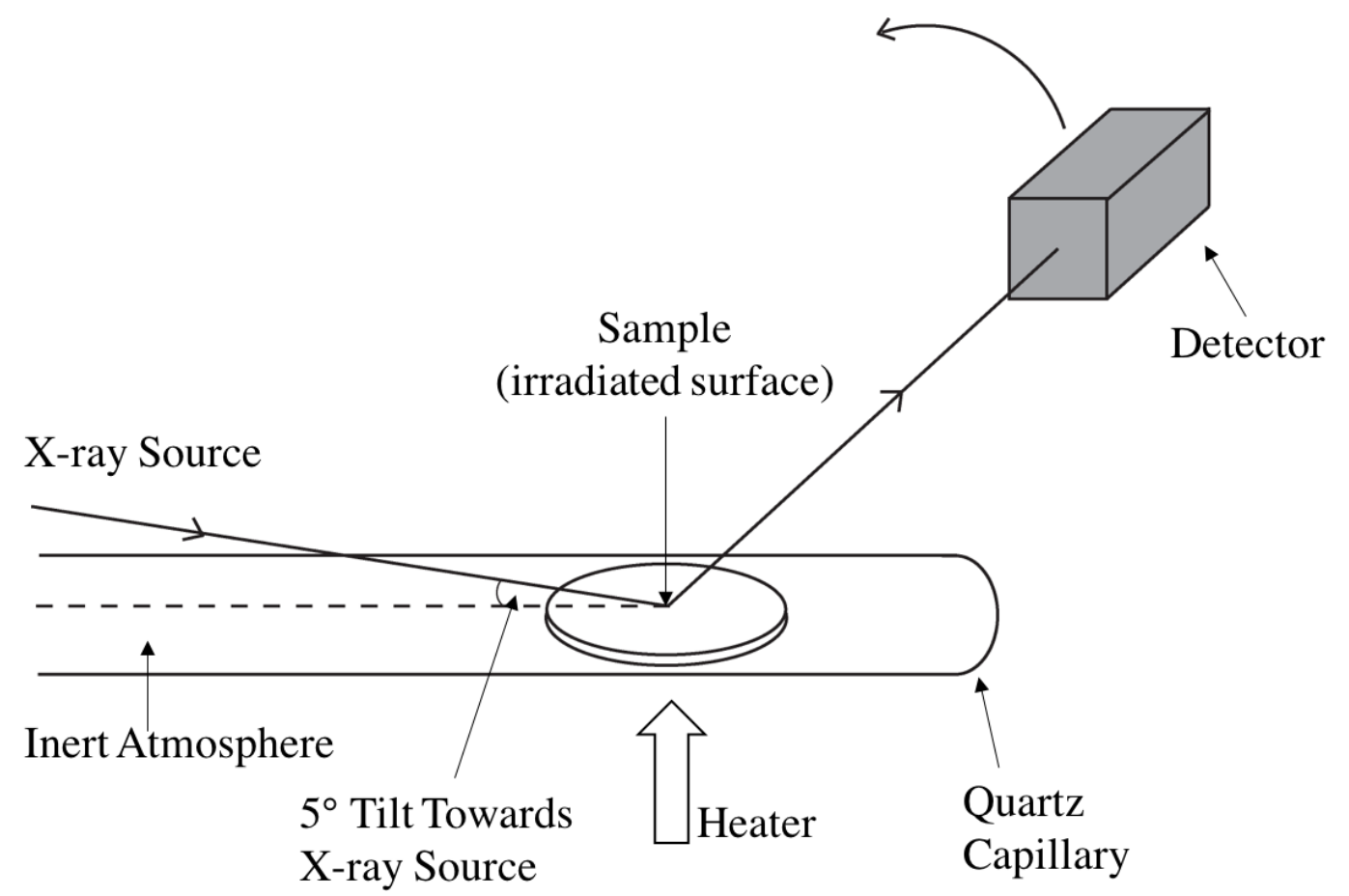

Figure 2. Schematic of in-situ, grazing incident synchrotron X-ray diffraction setup.
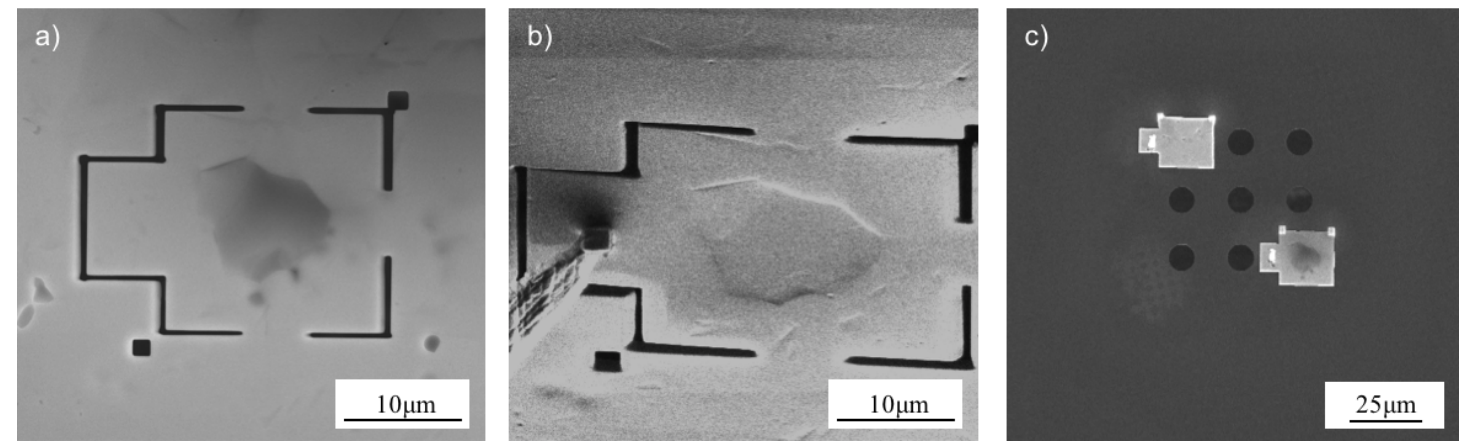

Figure 3. Preparation of the sample for in-situ annealing in a TEM carried out using FIB milling. a) Secondary electron image showing cuts made using $\mathrm{Ga}$ ion beam on an electropolished foil. The dark contrast in the middle of the cuts is the thin grain of interest. b) ion beam image showing the Omniprobe attached to the sample prior to the final cuts. c) Secondary electron image showing the sample placed onto the Protochips Aduro Thermal E-chip. The irradiated sample is attached in the bottom right of the chip and a non-irradiated grain is placed in the top left. The area of interest was placed over one of the portholes in the heating chip. 


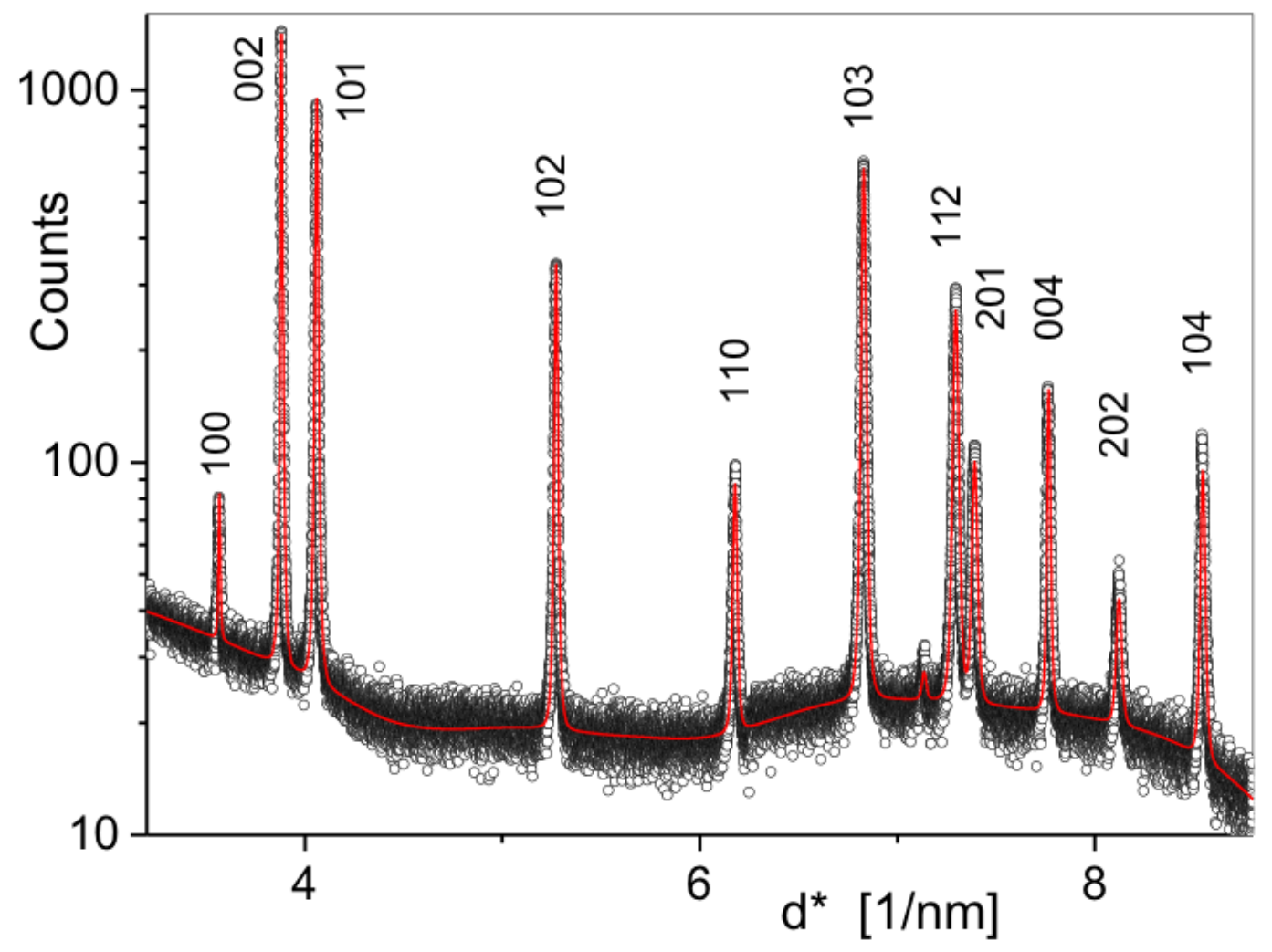

Figure 4. A typical example of a full SXRD pattern analysed with CMWP. The black open circles represent the experimental data and the red line is the fitted profile generated in CMWP.
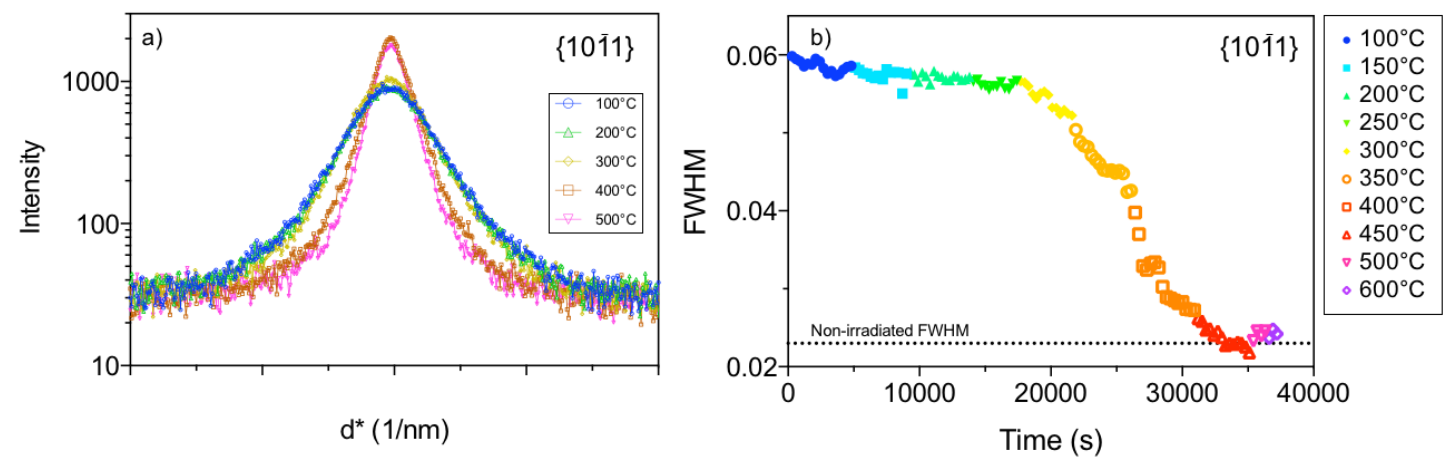

Figure 5. a) Variation of $\{10 \overline{1} 1\}$ peak shape during the in-situ annealing experiment. The peak centres have been aligned with the $100^{\circ} \mathrm{C}$ peak to highlight the shape change. b) Variation of full width half maximum (FWHM) of the $\{10 \overline{1} 1\}$ peak during annealing. Each symbol change represents measurements taken at a different target temperature. The dashed line indicates the FWHM of a non-irradiated sample. 


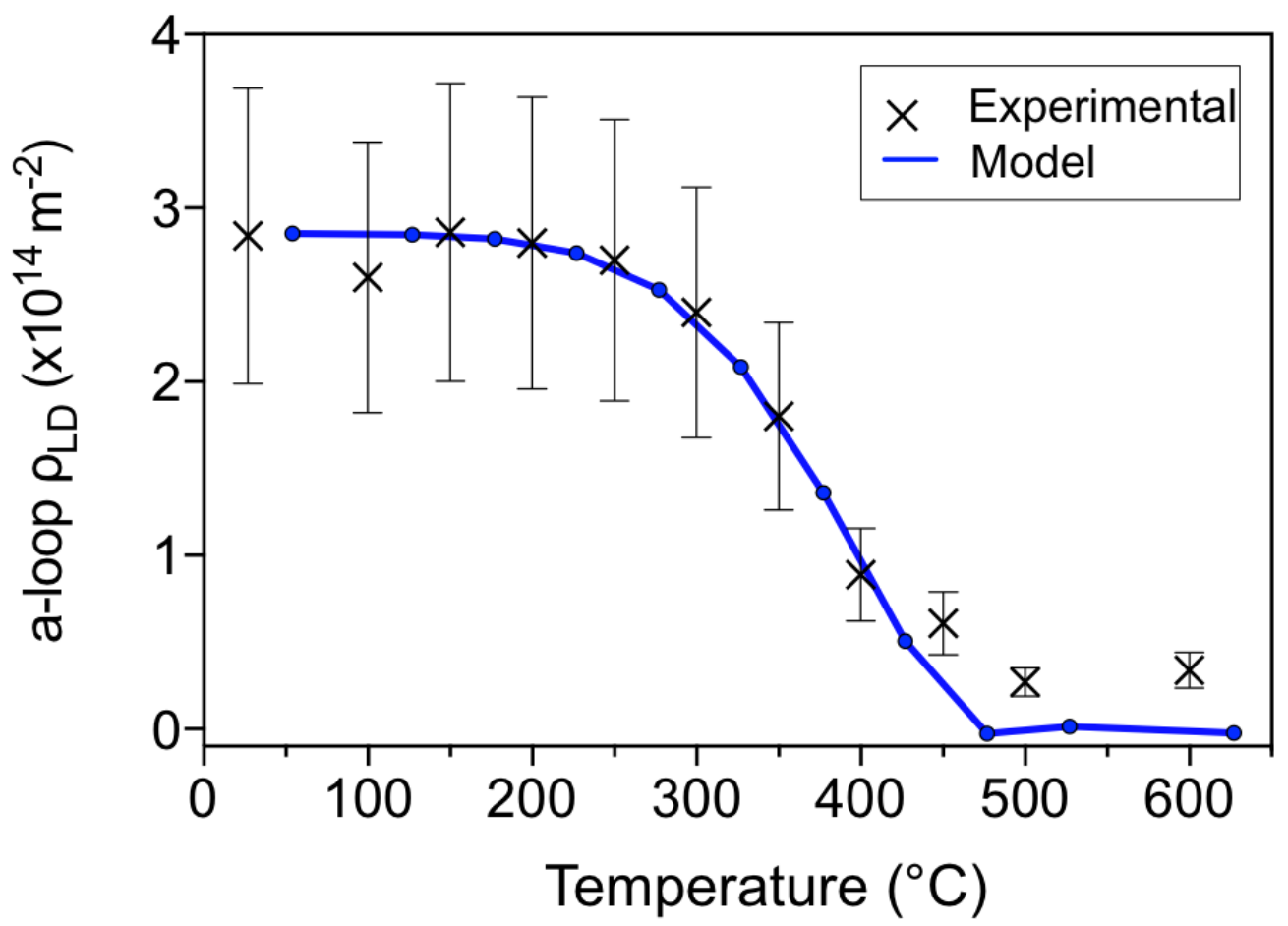

Figure 6. a-loop dislocation density as a function of annealing temperature, calculated from CMWP analysis of SXRD patterns. The blue line represents the evolution of line density based on a model used to calculate the effective activation energy generated from an Arrhenius equation (see supplementary material for the activation energy calculation). 

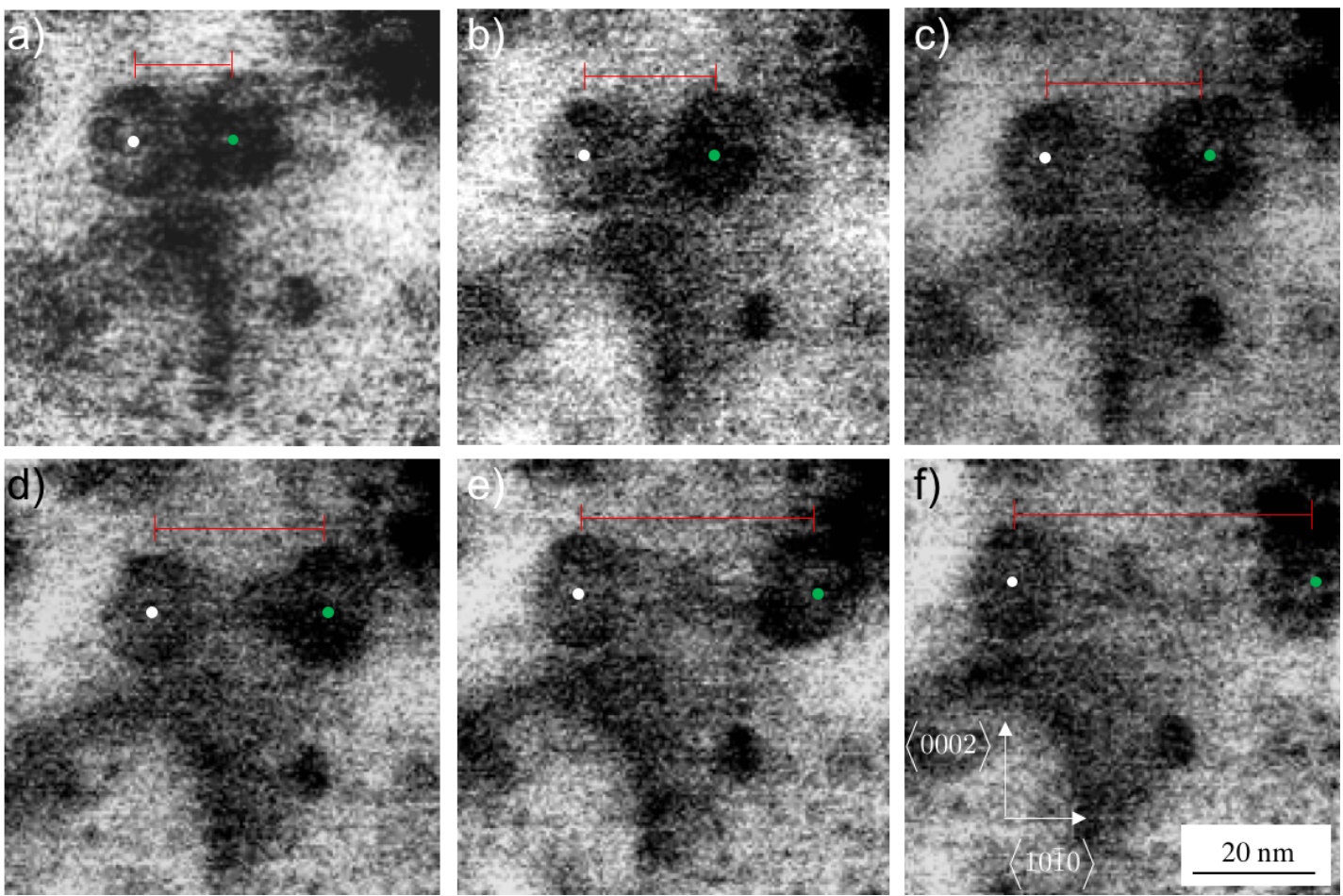

Figure 7. (a)-(f) BF-STEM images displaying the movement of an a-loop during in-situ annealing of the $1.5 \mathrm{dpa} \mathrm{Zr}$ $0.1 \mathrm{Fe}$ sample in the TEM at $425^{\circ} \mathrm{C}$. All images were taken at the $\langle 11 \overline{2} 0\rangle$ zone axis and are the same magnification. The red markers indicate the movement of a one a-loop from another. The white spot is the centre of one a-loop that does not move and the green spot indicates the centre of the moving loop. Small dark spots are seen in all of the images and are Pt deposits on the sample surface from the FIB lift out procedure. The time elapsed between a) and f) is 134 seconds with a total movement of $49 \mathrm{~nm}$. 


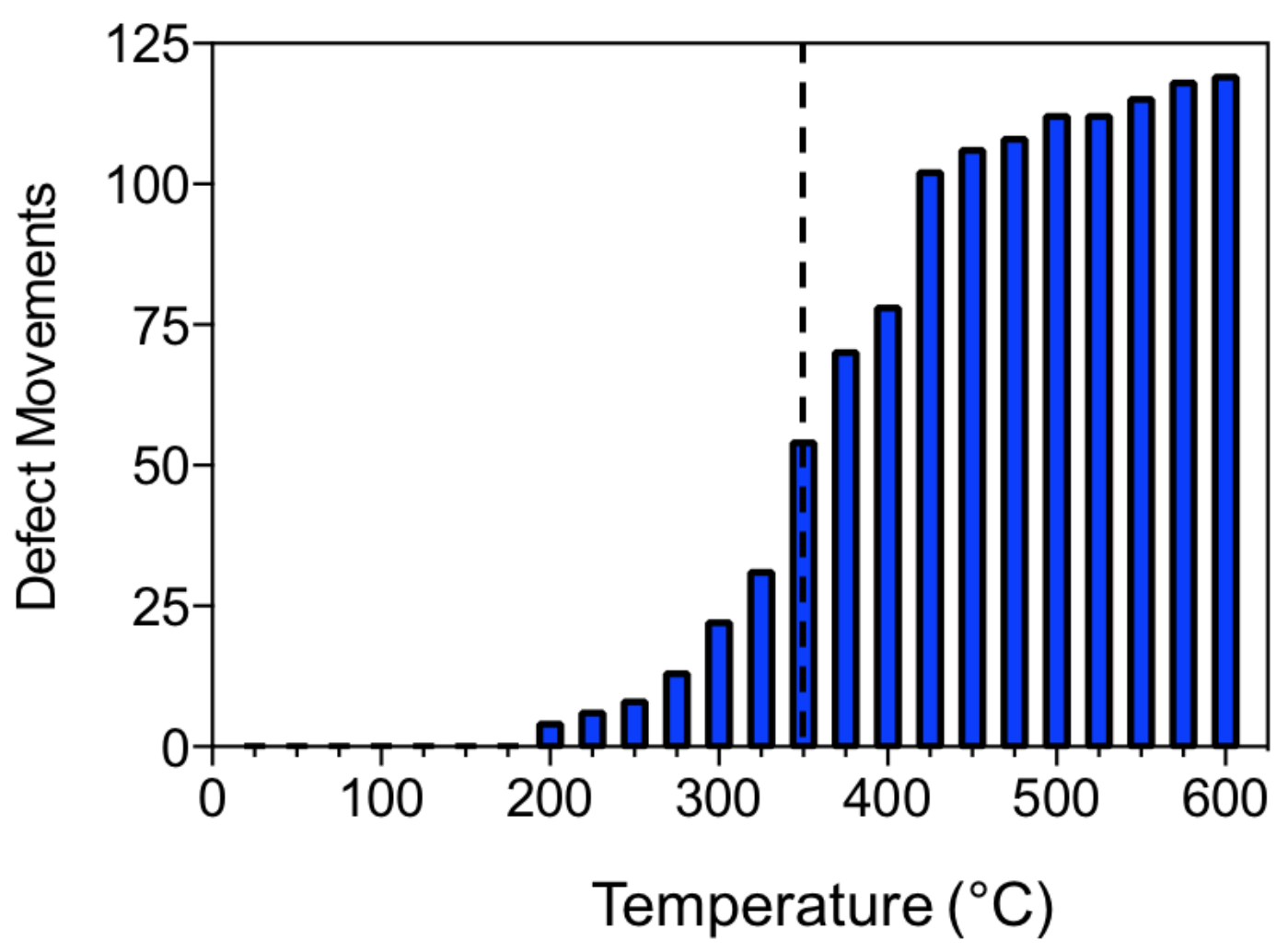

Figure 8. Cumulative number of defect movements initiated during in-situ annealing in TEM of $\mathrm{Zr}-0.1 \mathrm{Fe} 1.5 \mathrm{dpa}$ sample as a function of temperature. Area imaged was $3 \times 10^{5} \mathrm{~nm}^{2}$. The dashed line represents the irradiation temperature $\left(350^{\circ} \mathrm{C}\right)$. 